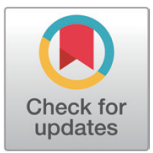

Received: May 26, 2021

Revised: Jul 10, 2021

Accepted: Aug 24, 2021

${ }^{*}$ Corresponding author

Yahya Ebrahimnezhad

Department of Animal Science,

Shabestar Branch, Islamic Azad

University, Shabestar, East Azerbaijan,

Iran.

Tel: +98-41-4242-5311

E-mail: ebrahimnezhad@gmail.com

Copyright ( $\odot 2021$ Korean Society of Animal Sciences and Technology.

This is an Open Access article distributed under the terms of the Creative Commons Attribution

Non-Commercial License (http:// creativecommons.org/licenses/by$\mathrm{nc} / 4.0 /$ ) which permits unrestricted non-commercial use, distribution, and reproduction in any medium, provided the original work is properly cited.

ORCID

Mohammad Ghasemi-Sadabadi

https://orcid.org/0000-0002-8508-0235

Yahya Ebrahimnezhad

https://orcid.org/0000-0001-6195-9520

Naser Maheri-Sis

https://orcid.org/0000-0001-6261-3273

Jamshid Ghiasi Ghalehkandi

https://orcid.org/0000-0001-6542-3563

Abdolahad Shaddel-Teli

https://orcid.org/0000-0002-3293-4639

Competing interests

No potential conflict of interest relevant to this article was reported.

Funding sources

Not applicable.

\section{Immune response and antioxidant status of broilers as influenced by oxidized vegetable oil and pomegranate peel}

\author{
Mohammad Ghasemi-Sadabadi, Yahya Ebrahimnezhad*, Naser Maheri-Sis, \\ Jamshid Ghiasi Ghalehkandi and Abdolahad Shaddel-Teli \\ Department of Animal Science, Shabestar Branch, Islamic Azad University, Shabestar, East Azerbaijan, Iran
}

\section{Abstract}

The experiment was designed as a $3 \times 3 \times 2$ factorial arrangement of treatments, including (i) pomegranate peel (zero, $4 \%$, and 8 percent), (ii) oxidized soybean oil (zero, $2 \%$, and 4 percent), and (iii) alpha-tocopherol (zero and $200 \mathrm{mg} / \mathrm{kg}$ ). Supplementation of $8 \%$ pomegranate peel in diets significantly decreased the growth performance of broiler chickens. The supplementation of $4 \%$ oxidized oil in diets significantly reduced body weight gain and Feed intake whole experimental period $(p<0.05)$. The results showed that supplementation of $4 \%$ pomegranate peel in the diet was associated with low aspartate transaminase (AST), alanine transaminase, and malondialdehyde (MDA). However, 4\% pomegranate peel increased the total antioxidant capacity (TAC) and superoxide dismutase (SOD) and glutathione peroxidase (GPx) activities. The supplemental $4 \%$ oxidized oil increased the serum AST, alanine aminotransferase (ALT), and MDA concentrations. TAC, SOD, and Catalase (CAT) activities were affected by $4 \%$ oxidized oil and alpha-tocopherol. The use of oxidized oil and vitamin $E$ decreased MDA concentration. The serum glucose and globulin concentrations were significantly lower in the $8 \%$ pomegranate peel. The results showed that supplementation with $4 \%$ pomegranate peel in diets reduced serum low-density lipoprotein (LDL). The inclusion of $4 \%$ oxidized oil in diets reduced serum glucose and increased the blood lipid concentration such as triglyceride, cholesterol and LDL. Vitamin E supplementation reduced the serum cholesterol and LDL concentrations. The use of $8 \%$ pomegranate peel reduced red blood cell (RBC), hemoglobin, and packed cell value (PCV). The results indicated that supplementation with $8 \%$ pomegranate peel and $4 \%$ oxidized oil in diets decreased the immunoglobulin concentration in broilers. In addition, it was found that the inclusion of $4 \%$ pomegranate peel in diets resulted in higher lgG, IgM and total immunoglobulin. Pomegranate peel supplementation significantly decreased meat MDA concentration. Supplementation of $4 \%$ oxidized oil increased MDA of meat $(p<0.05)$. Vitamin E supplementation $(200 \mathrm{mg} / \mathrm{kg})$ significantly decreased MDA of meat $(p<0.05)$. Consequently, the results of this experiment showed that supplementation with $4 \%$ pomegranate peel had beneficial effects on broiler chickens. It was also found that feeding $2 \%$ oxidized oil in diets had no adverse effect on broilers.

Keywords: Alpha-tocopherol, Blood, Broiler, Oxidized oil, Pomegranate peel 
Acknowledgements

This article is part of $\mathrm{PhD}$ thesis by

Mohammad Ghasemi-Sadabadi in

Animal Science, Islamic Azad University,

Shabestar Branch (thesis supervisor: Yahya

Ebrahimnezhad and Naser Maheri-Sis). The

authors would like to thank all staff of Islamic

Azad University, Shabestar Branch, for

providing the necessary facilities for carrying

out this research. Thanks also to Dr. Hossein

Janmohammadi (Professor of Poultry

Nutrition, University of Tabriz) for his kind

help of this study. Also, thanks to Professor

Paul Siegel for editing this paper.

Availability of data and material Upon reasonable request, the datasets of this study can be available from the corresponding author.

Authors' contributions

Conceptualization: Ebrahimnezhad Y, Maheri-Sis N

Data curation: Ghasemi-Sadabadi M, Ebrahimnezhad Y

Formal analysis: Ghasemi-Sadabadi M, Ebrahimnezhad $\mathrm{Y}$.

Methodology: Ebrahimnezhad Y, Maheri-Sis N, Ghalehkandi JG, Shaddel-Teli A

Software: Ghasemi-Sadabadi M,

Ebrahimnezhad $Y$.

Validation: Ebrahimnezhad Y, Maheri-Sis N.

Investigation: Ghasemi-Sadabadi M, Ebrahimnezhad Y, Maheri-Sis N.

Writing - original draft: Ghasemi-Sadabadi M, Ebrahimnezhad $Y$.

Writing - review \& editing: GhasemiSadabadi M, Ebrahimnezhad Y, MaheriSis N, Ghalehkandi JG, Shaddel-Teli A.

Ethics approval and consent to participate The research protocol utilized in this investigation was approved by the Animal Care and Use Committee of the Islamic Azad University, Iran (93/987-2014).

\section{INTRODUCTION}

Feed cost is one of the important keys to the poultry industry economy. Thus, farmers and nutritionists have attempted to improve efficiency and reduce the costs of feedstuffs. Accordingly, one way to reduce feed costs in diets is to replace them with affordable feedstuffs [1]. Farmer inclinations, availability, and low cost of oxidized oil (waste oil) allow it to be an essential source of poultry feedstuff. Furthermore, the use of waste oil in poultry diets may decrease environmental contamination [2]. In general, utilizing vegetable oils seems necessary for fast-growing broilers to meet energy and essential fatty acid requirements. It has been demonstrated that approximately $8 \%$ of oil can be used in high-energetic diets in broilers [3]. Generally, the rapid growth of urbanization, changing lifestyles, consumption patterns, and rising fast-food consumption has led to an increase in waste oils and municipal wastes [4]. The disposal of waste oils has contributed to environmental pollution [2]. Scientists are concerned about feeding with oxidized oil because it causes oxidative stress in the body, which increases the risk of cancer and other diseases in humans and animals. Previous studies have emphasized the problems of highly oxidized oils that are rich in various peroxides and malondialdehyde (MDA) [2]. Waste oils in poultry diets increase oxidative stress by increasing free radicals in the body, which reduces growth performance, intestinal health, antioxidant activity, and meat quality [2]. It has been noted that the oxidation process changes the chemical and physical indices of oil, thereby reducing its quality [5]. Oxidation is a destructive process that affects lipids, pigments, proteins, DNA, carbohydrates, and vitamins [6], and it can be harmful to health. Similarly, Ghasemi-Sadabadi et al. [2] reported that feeding oxidized soybean oils with $45.18,101.99$, and $146.03 \mathrm{meq} / \mathrm{kg}$ peroxide had harmful effects on immune response, antioxidant activity, intestinal health, and meat quality of Japanese quail. In contrast, the use of high peroxide value oil did not affect the health and performance of broiler chickens. Tan et al. [7] showed that the inclusion of soybean oil with $24.4,56.8$, and $73.2 \mathrm{meq} / \mathrm{kg}$ peroxide value did not significantly influence broiler chickens. Overall, the addition of oxidized oil to the diet increases atherosclerosis, blood cholesterol, and low-density lipoprotein (LDL) concentrations and decreases immunoglobulin concentrations [8]. Oxidation reactions produce harmful peroxides, such as hydrocarbons, hydrocarbons, ketones, alcohols, organic acids, and aldehydes that contain mutagenic and carcinogenic agents. In addition, these products reduce vitamins and carotenoids in the body. Furthermore, these compounds lead to oxidative stress in the body by increasing reactive oxygen species (ROS) levels [5].

Plant products are food additives that improve the feed efficiency and performance of animals. Researchers have highlighted the importance of by-products of plant products in various polyphenols and other beneficial components [9]. Researchers have reported that plant products can be replaced by other dietary sources in birds [10]. Pomegranate peel is a by-product of the pomegranate juice and paste industry and is discarded without any utilization [11]. Pomegranate peel constitutes about $40 \%$ of the fruit and can be used as a residue by-product [12]. According to previous investigations, pomegranate by-products contain medicinal properties and sufficient nutrients that can replace expensive foodstuffs in poultry feed [10]. Pomegranate peel has antioxidant, antibacterial, and anti-inflammatory effects, which can have a positive impact on glucose, insulin, fat, and blood pressure. Consequently, it improves cellular immunity, prevents fat oxidation, and increases the growth performance and immune response of birds [13]. These products contain a high amount of polyphenol antioxidants, such as tannins. Numerous antioxidant compounds in pomegranate peel are hydrolyzable tannins and contain gallotannins, ellagitannins, and gallagyl esters, such as punicalagin and punicalinin in condensed tannins [14]. Moreover, the most important phenolic compounds in peel include gallic acid, ellagic acid, punicalin, punicalagin, 
anthocyanidins, and flavonoids [11]. The researchers found that the pomegranate peel contained $2,850 \mathrm{kcal} / \mathrm{kg}$ metabolizable energy, $4 \%$ crude protein $(\mathrm{CP})$, and $3 \%$ crude fat and could be replaced with other ingredients in poultry diets. Moreover, they reported that adding $7.5 \%$ pomegranate peel to the diet improved the growth performance of Japanese quails [10]. Tannins consumed with pomegranate peel interfered with the digestibility of protein and calcium [15], which could have harmful effects on growth and other traits. Natural or commercial antioxidants have been shown to reduce the harmful effects of oxidized oil $[8,16]$. Therefore, pomegranate peel seems to be a powerful antioxidant that can prevent oil peroxidation and its related problems in broilers. Therefore, feeding pomegranate peel and waste oils (oxidized oil) to broilers reduces the cost of diet and environmental pollution. Thus, the present study aimed to investigate the effect of pomegranate peel powder and waste oil in diets on the immune response, antioxidant status, and intestinal health of broilers.

\section{MATERIALS AND METHODS}

\section{Oil preparation}

Soybean oil was purchased from the market, was poured into a metal gallon for the oxidation process. In this study, soybean oil was warmed up for 18 hours at $180^{\circ} \mathrm{C}$. The oils were also aerated by an air pump during the heating process. After the oxidation time, oxidized soybean oil was stored at $-20^{\circ} \mathrm{C}$ to prevent further changes in oil composition. Previous researches showed that cold storage kept the chemical composition of these products [2]. The chemical characteristics of oxidized and fresh oil were analyzed after the oxidation process of soybean oil. For this purpose, the oil samples were drained into a laboratory bottle, labeled and transferred to the food analysis laboratory. In the laboratory, peroxide values, MDA contents, and anisidine value of oxidized oil and fresh oil were analyzed according to the methods of Harwood and Aparicio [17]. The chemical properties of oils are presented in Table 1.

\section{Pomegranate peel composition}

Pomegranate peels obtained from the pomegranate processing factory were dried, were milled and prepared for the experiment. Before starting the trial, the chemical compositions of peels were measured in the animal food lab of Azad University of Shabestar (Table 2). The gross energy (GE) of pomegranate peel was measured through an adiabatic bomb calorimeter (Parr Instrument Company, Moline, IL, USA) [18]. Methionine, lysine and threonine of pomegranate peels was measured according to the method described by the AOAC [19] and Cooperative [20] using high performance liquid chromatography (HPLC) and the modification of PICO-TAG methods. AOAC methods were used to measure dry matter (DM), CP, ether extract (EE), crude fiber (CF), and ash of pomegranate peels [19]. Besides, the content of total polyphenol, hydrolysable tannins, and condensed tannins of pomegranate peel were estimated utilizing methods reported by Saleh et

Table 1. Analysis of the chemical composition of experimental soybean oils

\begin{tabular}{|c|c|c|}
\hline Item & Normal soybean oil & Oxidized soybean oil \\
\hline $\mathrm{PV}$ (meq/kg) & $2.07 \pm 0.10$ & $49.03 \pm 1.98$ \\
\hline MDA $(\mu \mathrm{g} / \mathrm{kg})$ & $3.53 \pm 0.29$ & $56.12 \pm 2.42$ \\
\hline AnV & $2.09 \pm 0.14$ & $198 \pm 3.89$ \\
\hline
\end{tabular}

Soybean oil was heated up for $18 \mathrm{~h}$ at $180^{\circ} \mathrm{C}$.

Results are the average of four analyses $\pm \mathrm{SD}$.

$\mathrm{PV}$, peroxide value; MDA, malondialdehyde; AnV, anisidine value. 
Table 2. Nutritive and chemical contents of pomegranate peel

\begin{tabular}{lc}
\hline \multicolumn{1}{c}{ Item } & Pomegranate peel \\
\hline Gross energy (kcal/kg) & 4,478 \\
Apparent metabolizable energy (AME, kcal/kg) & 1,835 \\
Nitrogen-corrected apparent metabolizable energy (AMEn, kcal/kg) & 1,833 \\
True metabolizable energy (TME, kcal/kg) & 2,475 \\
Nitrogen-corrected true metabolizable energy (TMEn, kcal/kg) & 2,470 \\
Dry matter (\%) & 91.66 \\
Crude protein (\%) & 5.20 \\
Crude fat (\%) & 1.42 \\
Crude fiber (\%) & 17.96 \\
Ash (\%) & 3.37 \\
Nitrogen free extract (NFE) (\%) & 72.05 \\
Lysine (\%) & 0.20 \\
Methionine (\%) & 0.09 \\
Threonine (\%) & 0.05 \\
Arginine (\%) & 0.25 \\
Total polyphenol content (mg gallic acid equivalents/g dry matter) & 179.21 \\
hydrolysable tannins (mg tannic acid/g dry matter) & 203.12 \\
Condensed tannins (mg cyaniding acid/g dry matter) & 6.05 \\
\hline
\end{tabular}

al. [21]. The pomegranate peels compound are shown in Table 2.

\section{Sibbald methods}

At 54 days of age, 10 roosters from a group of 20 Ross 308 roosters weighing 3,300 $\pm 50 \mathrm{~g}$ were placed in individual cages to determine their metabolizable energy [22]. The roosters were kept in individual metabolism cages at $18^{\circ} \mathrm{C}-24^{\circ} \mathrm{C}$. Thirty grams of pomegranate peels were weighed in five replicates and poured into capped plastic dishes. The roosters fasted for $48 \mathrm{~h}$ to empty the gastrointestinal tract of food residues. All cages were divided into two parts: in the first part, the peel $(30 \mathrm{~g})$ was fed to five roosters using a Sibbald funnel, and the other five roosters fasted to estimate endogenous. Excreta from all cages were collected, weighed, and stored at $-18^{\circ} \mathrm{C}$ for chemical analyses. All excreta were dried in a forced-air draft oven at $70{ }^{\circ} \mathrm{C}$ for $48 \mathrm{~h}$, and GE and nitrogen were estimated using the AOAC [19] method. The excreta CP, EE, DM, and ash contents were determined according to AOAC [19]. The zero nitrogen retention was corrected using 8.22 $\mathrm{kcal} / \mathrm{g}$ of retained nitrogen. The pomegranate peel powder apparent metabolizable energy (AME), nitrogen-corrected apparent metabolizable energy (AMEn), true metabolizable energy (TME), and nitrogen-corrected true metabolizable energy (TMEn) were calculated using the following equations, and they are shown in Table 2 [18].

1- AME $(\mathrm{kcal} / \mathrm{kg})=[$ feed intake $(\mathrm{FI}, \mathrm{g}) \times \mathrm{GE}$ of diet $(\mathrm{kcal} / \mathrm{g})-\{$ excreta content $(\mathrm{g}) \times \mathrm{GE}$ of excreta $(\mathrm{kcal} / \mathrm{g})\}]$ / FI (g).

2- AMEn $(\mathrm{kcal} / \mathrm{kg})=[\mathrm{FI}(\mathrm{g}) \times \mathrm{GE}$ of diet $(\mathrm{kcal} / \mathrm{g})-\{$ excreta content $(\mathrm{g}) \times \mathrm{GE}$ of excreta $(\mathrm{kcal} / \mathrm{g})+$ $\{\mathrm{FI}(\mathrm{g}) \times$ nitrogen of diet $(\mathrm{g} / \mathrm{g})$ - excreta content $(\mathrm{g}) \times$ nitrogen of excreta $(\mathrm{g} / \mathrm{g})\} \times 8.22\}] / \mathrm{FI}(\mathrm{g})$. 3- TME $(\mathrm{kcal} / \mathrm{kg})=[\mathrm{FI}\{\mathrm{g}\} \times \mathrm{GE}$ of diet $\{\mathrm{kcal} / \mathrm{g}\}-\{$ excreta content $(\mathrm{g}) \times \mathrm{GE}$ of excreta $(\mathrm{kcal} / \mathrm{g})+$ metabolic faecal energy $(\mathrm{kcal} / \mathrm{g})+$ indigenous urinary energy $(\mathrm{kcal} / \mathrm{g})\}]$ / FI (g).

4- TMEn $(\mathrm{kcal} / \mathrm{kg})=[\{\mathrm{FI}(\mathrm{g}) \times \mathrm{GE}$ of diet $(\mathrm{kcal} / \mathrm{g})\}-\{$ excreta content $(\mathrm{g}) \times \mathrm{GE}$ of excreta $(\mathrm{kcal} /$ $\mathrm{g})\}-\{$ nitrogen retention $(\mathrm{g}) \times 8.22\}]+$ \{metabolic faecal energy $(\mathrm{kcal} / \mathrm{g})+$ indigenous urinary 
energy $(\mathrm{kcal} / \mathrm{g})\}+\{$ nitrogen retention at zero level for control group $(\mathrm{g}) \times 8.22\}] / \mathrm{FI}(\mathrm{g})$. Nitrogen retention $(\mathrm{g})=\mathrm{FI}(\mathrm{g}) \times$ feed nitrogen $(\%)-$ excreta $(\mathrm{g}) \times$ faecal nitrogen $(\%)$.

\section{Animals, breeding and nutrition}

The research protocol utilized in this investigation was approved by the Animal Care and Use Committee of the Islamic Azad University (93/987-2014) [23]. The experiment was designed according to a $3 \times 3 \times 2$ factorial arrangement, with factors i) the pomegranate peel powder (zero, 4 and 8 percent in diets), ii) the oxidized oil (zero, 2 and 4 percent in diets) and iii) the vitamin $\mathrm{E}$ (zero and $200 \mathrm{mg} / \mathrm{kg}$ ). The commercial vitamin $\mathrm{E}$ in this experiment (Golbar-Chemi ${ }^{\circledR}$; www. golbargroup.com, www.Golbar-chemi.com), is a powder vitamin $\mathrm{E}$ supplement that contains 5,500 IU vitamin E. Hence, a total of 1,080 day old, male Ross 308 strain broiler chicken, were randomly allocated to 90-floor pens in a completely randomized design with 18 treatments and five replicates with 12 chicks in each replicate. The chicks were fed commercial diets during the ten days of the experiment. At end of $10 \mathrm{~d}$, the chicks were weighed and housed in $1.5 \times 1.5 \mathrm{~m}$ floor pens each equipped with a pan feeder and manual drinker. Feed and water were available ad libitum. All chicks in the treatment groups were fed a grower (10-24 days) and finisher diet from (25-42 days). All diets were formulated based on nutritional requirements proposed by the NRC [24]. Also, the proximate composition of diets $\mathrm{CP}, \mathrm{EE}$ and $\mathrm{CF}$ were measured according to $\mathrm{AOAC}$ [19] methods. The basal diets in this experiment were corn and soybean meal so that different percentages of pomegranate peel powder, oxidized soybean oil, and vitamin $\mathrm{E}$ were added to the basal diets. All diets are shown in Tables 3 and 4 .

\section{Performance}

The performance of broilers in terms of body weight gain (BWG), FI, and feed conversion ratio $(\mathrm{FCR})$ at the end of total rearing period (d 11-42) were determined. Production index (PI) for the total rearing period (d 11-42) was calculated [25].

\section{Blood parameters}

A broiler from each pen was selected at the end of the experiment then five $\mathrm{mL}$ of blood samples were collected from the wing vein. All samples were centrifuged at 3,000 xg for 15 minutes and serum samples were stored at $20^{\circ} \mathrm{C}$ for further analysis. The biochemical parameters including glucose, triglyceride (TG), cholesterol, LDL, high density lipoprotein (HDL), urea, uric acid, total protein [26], albumin, aspartate aminotransferase (AST), alanine aminotransferase (ALT) [27] and alkaline phosphatase (ALP) were determined by a Technicon RA-1000 auto-analyzer according to the manufacturer's recommendations (Pars Azmoon, Tehran, Iran). In addition, the serum globulin concentration was calculated by the subtraction between total protein and albumin [23]. Enzyme activities, including serum superoxide dismutase (SOD) [28], glutathione peroxidase (GPx), and total antioxidant capacity (TAC) in serum were analyzed according to the method using the RANSEL and RANSOD kits (Randox Laboratories, Crumlin, Antrim, UK). The serum MDA concentration in the homogenates, was displayed as nmol/g, was determined by the Jo and Ahn [29] method. Furthermore, the catalase (CAT) concentration of blood was measured according to the method of Aebi [30].

\section{Hematology parameters}

On days 42 , one broilers from each cage was selected and blood samples were collected from the vein wings. Blood samples were drained into tubes with anticoagulant (EDTA one $\mathrm{mg} / \mathrm{mL}$ blood). Red blood cell (RBC) and white blood cell (WBC) counts were determined utilizing the method 
๓

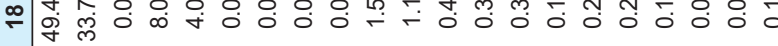

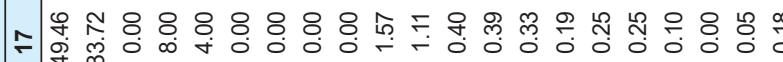
이

난

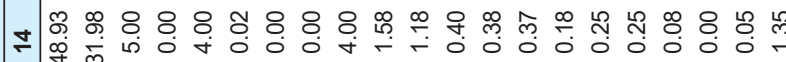

m

|ㅣㄹ

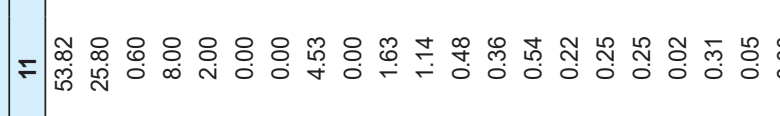

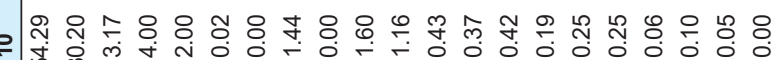
in

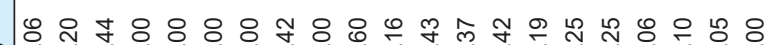
๑

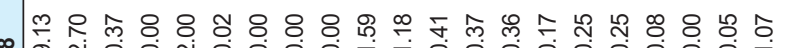

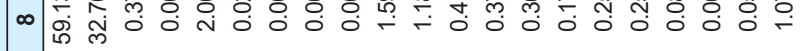
-

•

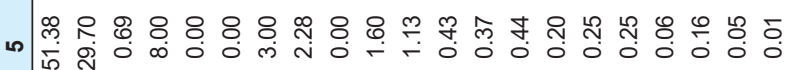

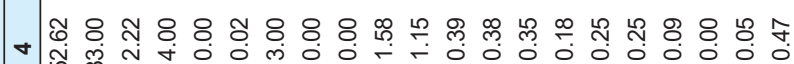

(용

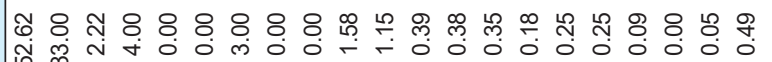

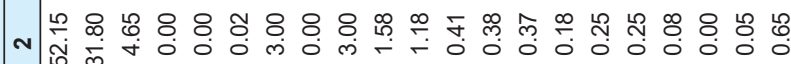

$-2$

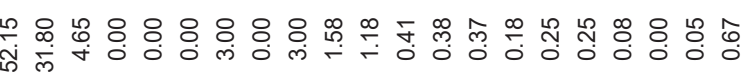

炼

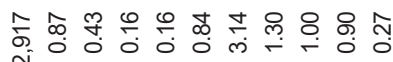

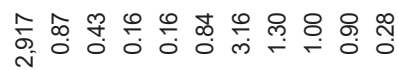

స్서

స̌

N $0000 \mathrm{mr}$

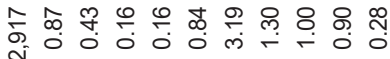

సิ

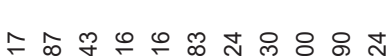

๙ু

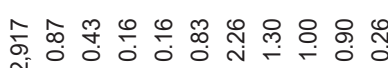

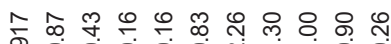

స̌

ㅅํㅇำ

๙্র

సᄒ⿱

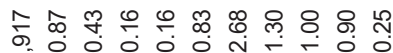

స్

กิร ๆ

h.

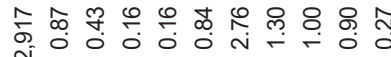

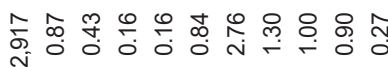

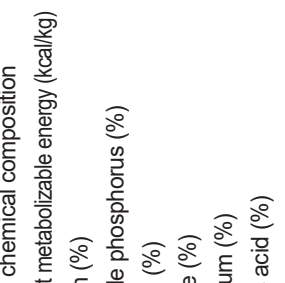

든 ํำ

(1)

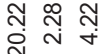

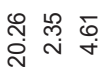

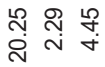

윰 ల్లి

స్ ఝ ๗

N

సָํำ

ำ กิ

$\infty$ 유

จ่

จิ์

กิ

సิ ণ

సָ

N

융 원

苍苍芦

กิ

กิ

$\stackrel{\sim}{\sim} \stackrel{\infty}{\sim} \stackrel{\infty}{\sim}$

ำ 宂 춘원

힌

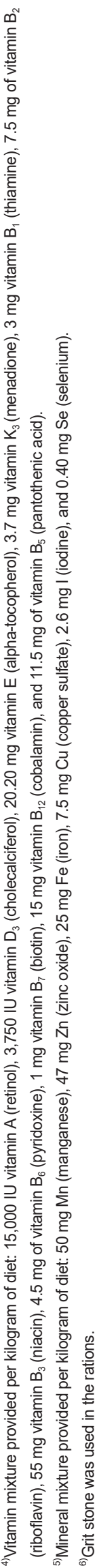




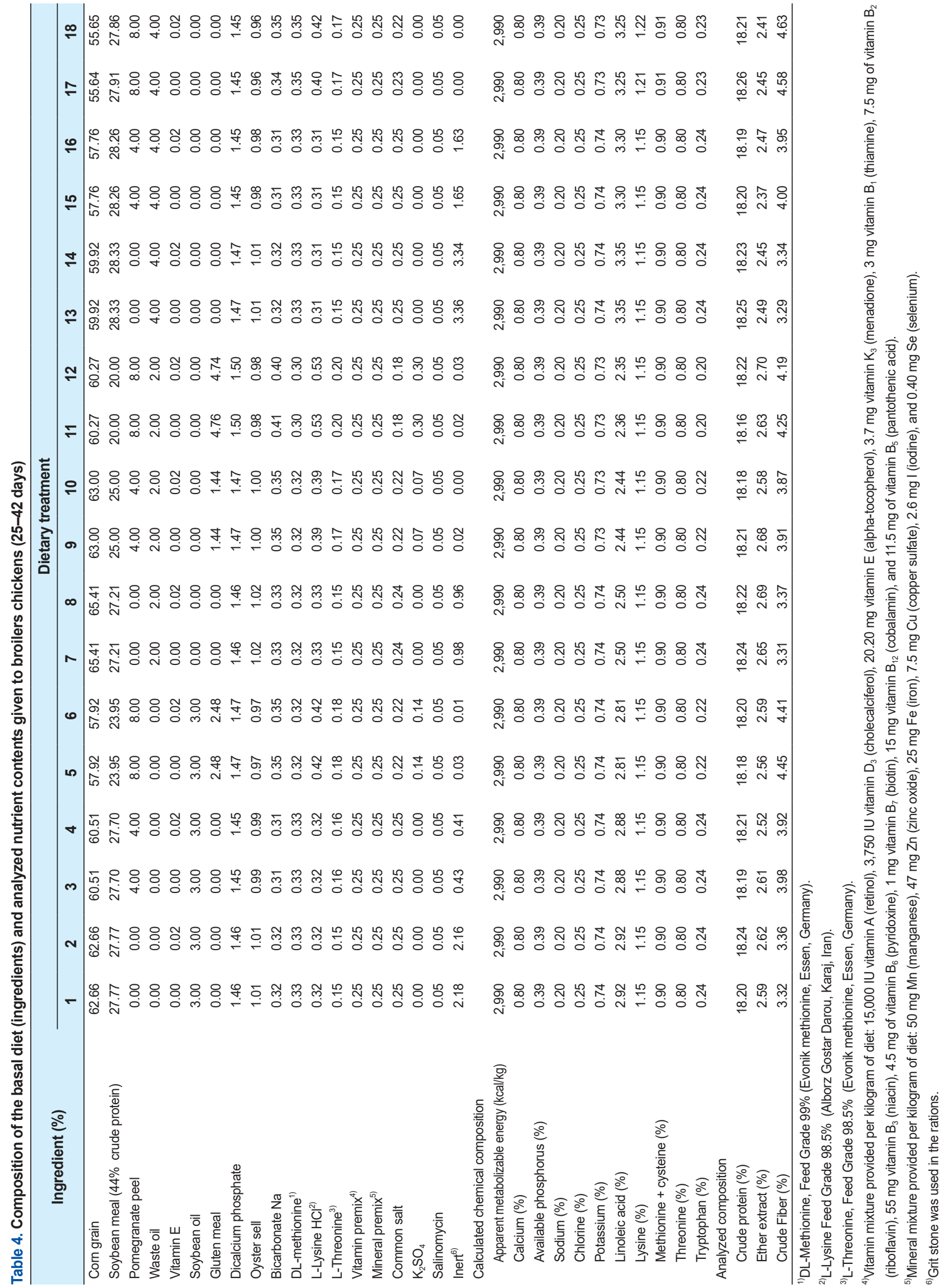


described by Natt and Herrick [31], and pack cell volume (PCV) of blood was measured by hematocrit tubes. Besides, according to the Cyanmethaemoglobin method, as shown by Benjamin [32], hemoglobin [33] was determined [23]. Also, blood smears were made to count lymphocytes and heterophils, which was measured.

\section{Blood immunoglobulin}

Three milliliters of 5\% suspension of sheep red blood cells (SRBCs) were injected into two broilers per pen for immunoglobulin $\mathrm{G}(\mathrm{IgG})$ and immunoglobulin $\mathrm{M}(\mathrm{IgM})$ determination at 35 days, and blood was obtained from the wing vein at the end of the experimental period. All samples were centrifuged, and all sera were properly labeled and stored at $-20^{\circ} \mathrm{C}$ for further studies. To analyze the total anti-SRBC antibodies, all sera were inactivated at $56^{\circ} \mathrm{C}$ for $30 \mathrm{~min}$ [34]. All samples were titrated for whole and mercaptoethanol (ME)-resistant ( $\operatorname{IgG})$ anti-SRBC antibody titers. MEsensitive (IgM) antibody titers were achieved by reducing the level (titer) of the IgG antibodies from the total antibodies, which was defined in terms of $\log 2$. [2].

\section{Meat quality}

At the end of the experiment, one broiler from each pen was slaughtered and the breast muscle was trimmed and stored at $-20^{\circ} \mathrm{C}$ in the freezer. Methods of Ghasemi-Sadabadi et al. [2] were evaluated as the best for measuring the amount of MDA.

\section{Statistical analysis}

Statistical analyses were performed using SAS software. The data were analyzed using a $3 \times 3 \times 2$ factorial arrangement design. Significant differences between treatments were separated using the Tukey range test at $(p<0.05)$. Also, linear and quadratic effects in this experiment were analyzed by using SAS statistical software [35].

\section{RESULTS AND DISCUSSION}

\section{Performance}

The effects of using different level of pomegranate peel powder, oxidized oil and alpha-tocopherol in the diet on performance in broiler chickens are shown in Table 5.

The results showed that feeding $8 \%$ pomegranate peel in diets redacted BWG, FI, FCR, and PI compared to other groups $(p<0.05)$. The results indicated that broilers fed diets with $4 \%$ waste oil had significantly lower BWG and FI when compared to broilers fed diets with $2 \%$ waste oil ( $p$ $<0.05$ ). Whereas, there was no significant difference between the control group and $2 \%$ waste oil supplemented treatments. As can be seen in tables, when vitamin $\mathrm{E}$ was supplemented into the diets BWG was increased between groups during total rearing period $(p<0.05)$.

The data demonstrated that when using $8 \%$ pomegranate peel in diets, growth performance of broilers. The results were quite similar to the results of [36]. However, no retarded growth was observed when using the lower inclusion level of $4 \%$ pomegranate peel. Abbas et al. [10] has reported that $7.5 \%$ pomegranate peel inclusion in diets did not affect growth performance of Japanese quail. Growth performance of the birds at high inclusion levels of pomegranate peel may be related to the high amount of tannins and CF of pomegranate peel [21]. It had been showed that polyphenol concentrations such as tannins with the addition of pomegranate peel diminished growth performance in broilers [1].

In this study, the data demonstrated that the supplementation of $4 \%$ waste oil in diets significantly reduced BWG and FI. The researchers showed that feeding of $4 \%$ waste oil in diets 
Table 5. The effects of using pomegranate peel powder, oxidized oil and alpha-tocopherol in diets on performance in broiler chickens (11-42 d)

\begin{tabular}{|c|c|c|c|c|c|c|}
\hline & \multirow{2}{*}{\multicolumn{2}{|c|}{ Treatment }} & \multicolumn{4}{|c|}{ Traits } \\
\hline & & & BWG (g) & $\mathrm{FI}(\mathrm{g})$ & FCR $(g / g)$ & PI \\
\hline Main effect & & & & & & \\
\hline 0 & & & $2,111.8^{\mathrm{a}}$ & $3,674.0^{\mathrm{a}}$ & $1.74^{\mathrm{a}}$ & $389.5^{a}$ \\
\hline 4 & & & $2,102.9^{\mathrm{a}}$ & $3,648.5^{\mathrm{a}}$ & $1.73^{\mathrm{a}}$ & $384.1^{\mathrm{a}}$ \\
\hline 8 & & & $1,772.0^{b}$ & $3,376.9^{b}$ & $1.90^{b}$ & $283.0^{b}$ \\
\hline Oxidizec & & & & & & \\
\hline 0 & & & $2,015.9^{a}$ & $3,607.7^{\mathrm{a}}$ & 1.79 & 352.9 \\
\hline 2 & & & $2,009.6^{a}$ & $3,573.7^{\mathrm{ab}}$ & 1.78 & 356.3 \\
\hline 4 & & & $1,961.2^{b}$ & $3,518.0^{b}$ & 1.80 & 347.5 \\
\hline SEM & & & 16.75 & 23.28 & 0.02 & 5.35 \\
\hline SEM & & & 13.68 & 19.00 & 0.01 & 4.34 \\
\hline Interaction & & & & & & \\
\hline Pomegr & oxid & ocophero & & & & \\
\hline 0 & 0 & 0 & $2,124.2$ & $3,705.4$ & 1.74 & 389.3 \\
\hline 0 & 0 & 200 & $2,177.9$ & $3,789.7$ & 1.74 & 392.4 \\
\hline 0 & 2 & 0 & $2,126.6$ & $3,654.9$ & 1.72 & 398.4 \\
\hline 0 & 2 & 200 & $2,163.5$ & $3,730.8$ & 1.72 & 398.9 \\
\hline 0 & 4 & 0 & $2,018.7$ & $3,547.5$ & 1.75 & 378.5 \\
\hline 0 & 4 & 200 & $2,059.7$ & $3,615.7$ & 1.75 & 379.6 \\
\hline 8 & 0 & 200 & $1,853.0$ & $3,463.5$ & 1.87 & 298.2 \\
\hline 8 & 2 & 0 & $1,787.2$ & $3,361.5$ & 1.88 & 291.2 \\
\hline 8 & 2 & 200 & $1,769.1$ & $3,385.0$ & 1.91 & 281.4 \\
\hline 8 & 4 & 0 & $1,728.0$ & $3,317.7$ & 1.92 & 274.8 \\
\hline 8 & 4 & 200 & $1,751.1$ & $3,360.6$ & 1.92 & 279.0 \\
\hline SEM & & & 41.1 & 57.10 & 0.03 & 13.06 \\
\hline$p$-value & & & & & & \\
\hline Pomegr & & & 0.0001 & 0.0001 & 0.0001 & 0.0001 \\
\hline Oxidizec & & & 0.0465 & 0.0270 & 0.7841 & 0.5070 \\
\hline Alpha-to & & & 0.0460 & 0.0614 & 0.5593 & 0.3281 \\
\hline Pomegr & xidi & & 0.2818 & 0.4995 & 0.9471 & 0.7896 \\
\hline Pomegr & aphe & & 0.7074 & 0.8038 & 0.9206 & 0.8456 \\
\hline Oxidizec & cop & & 0.9844 & 0.7364 & 0.8992 & 0.8502 \\
\hline Pomegr & xxidi & opherol & 0.6307 & 0.9954 & 0.7481 & 0.7556 \\
\hline
\end{tabular}

$a, b$ Means in columns with same superscript do not differ significantly $p<0.05$.

BWG, body weight gain; FI, feed intake; FCR, feed conversion ratio; PI, production index. 
reduced the growth performance of Japanese quail [2]. Previous research has shown that the supplementation of oxidized oil in diets jeopardizes growth performance [5,37,38]. It seems that the negative effect on performance with the inclusion of dietary oxidized oil may be related to higher peroxide value of waste oil [27]. The dietary $200 \mathrm{mg}$ vitamin E improved BWG in the current experiment. Other reports have also shown a beneficial effect of vitamin $\mathrm{E}$ supplementation on broiler growth performance.

\section{Blood enzymes activity}

The effects of using different level of pomegranate peel powder, oxidized oil and alpha-tocopherol in the diet on blood enzymes activity in broiler chickens are shown in Table 6. Also, linear and quadratic effects of pomegranate peel powder, oxidized oil and alpha-tocopherol and blood enzymes activity had shown in Table 7.

Based on the results obtained from this experiment, it was indicated that blood aspartate transaminase (AST), TAC, SOD, GPx, and MDA concentration in broilers were significantly affected by different level of pomegranate peel powder at end of experiment $(p<0.05)$. Broilers were fed $4 \%$ pomegranate peel powder indicated significantly lower AST and MDA compared with $8 \%$ pomegranate peel and control group $(p<0.05)$. The blood TAC, SOD, and GPx significantly increased by using $4 \%$ pomegranate peel in diets than other groups $(p<0.05)$. In addition, regarding the data, the AST, ALT, TAC, SOD, GPx, CAT, and MDA concentration was also affected by dietary oxidized oil $(p<0.05)$. The inclusion of $4 \%$ oxidized oil in diets significantly increased AST, ALT, and MDA in serum $(p<0.05)$. However, significant reductions were observed in the TAC, SOD, GPx, CAT on 4\% oxidized oil treatment than other groups $(p<0.05)$. Although there was a linear tendency to increased total AST and ALT concentrations, and decreased TAC, SOD, GPx, CAT with oxidized oil supplementation in the diet. Further, the inclusion of $4 \%$ oxidized oil in diets quadratically increased MDA concentration in blood. The current study finding indicated that the supplementation of alpha-tocopherol significantly affected blood TAC, SOD, GPx, and MDA concentrations at the end of the experiment $(p<0.05)$. The addition of $200 \mathrm{mg} /$ $\mathrm{kg}$ alpha-tocopherol in diets resulted in higher blood TAC, SOD, and CAT concentration $(p<$ 0.05). Whereas, the concentration of MDA was lower at $200 \mathrm{mg} / \mathrm{kg}$ alpha-tocopherol compared to not supplemented group $(p<0.05)$. Also, the supplementation of the alpha-tocopherol in diets had linearly affected the TAC, CAT, and MDA concentration in broilers $(p<0.05)$. Overall, the interaction was not observed between pomegranate peel powder, oxidized oil, and alpha-tocopherol in this study.

Serum AST enzyme concentrations were reduced by dietary 4\% pomegranate peel powder in this study. A reduction in AST concentration was also reported by Abdel Baset et al. [39] and Abbas et al. [10], where liver enzymes declined in pomegranate peel treatment. Therefore, Abbas et al. [10] reported that the addition of $2.5 \%$ pomegranate peel powder to diets reduced liver enzymes in Japanese quails. In contrast, Saleh et al. [21] stated that supplementation with $3 \mathrm{~g} / \mathrm{kg}$ pomegranate peel powder did not affect glutamic oxaloacetic transaminase (GOT) and glutamicpyruvic transaminase (GPT) enzymes. A previous study confirmed that phenolic compounds result in a decrease in AST concentrations in birds [2]. Hence, it seems that the antioxidant activity of pomegranate peel powder may protect the liver against oxidative stress, which inhibits liver tissue damage [36].

The results indicated that broilers fed $4 \%$ pomegranate peel powder had higher serum TAC, SOD, and GPx concentrations than the other groups. Overall, the body antioxidant defenses such as GPx, SOD, CAT, and other antioxidant products are visible in various tissues and serum at different concentrations and activities [40]. Similarly, Saleh [41] reported a marked improvement 
Table 6. The effects of using pomegranate peel powder, oxidized oil and alpha-tocopherol in diets on blood enzymes in broiler chickens

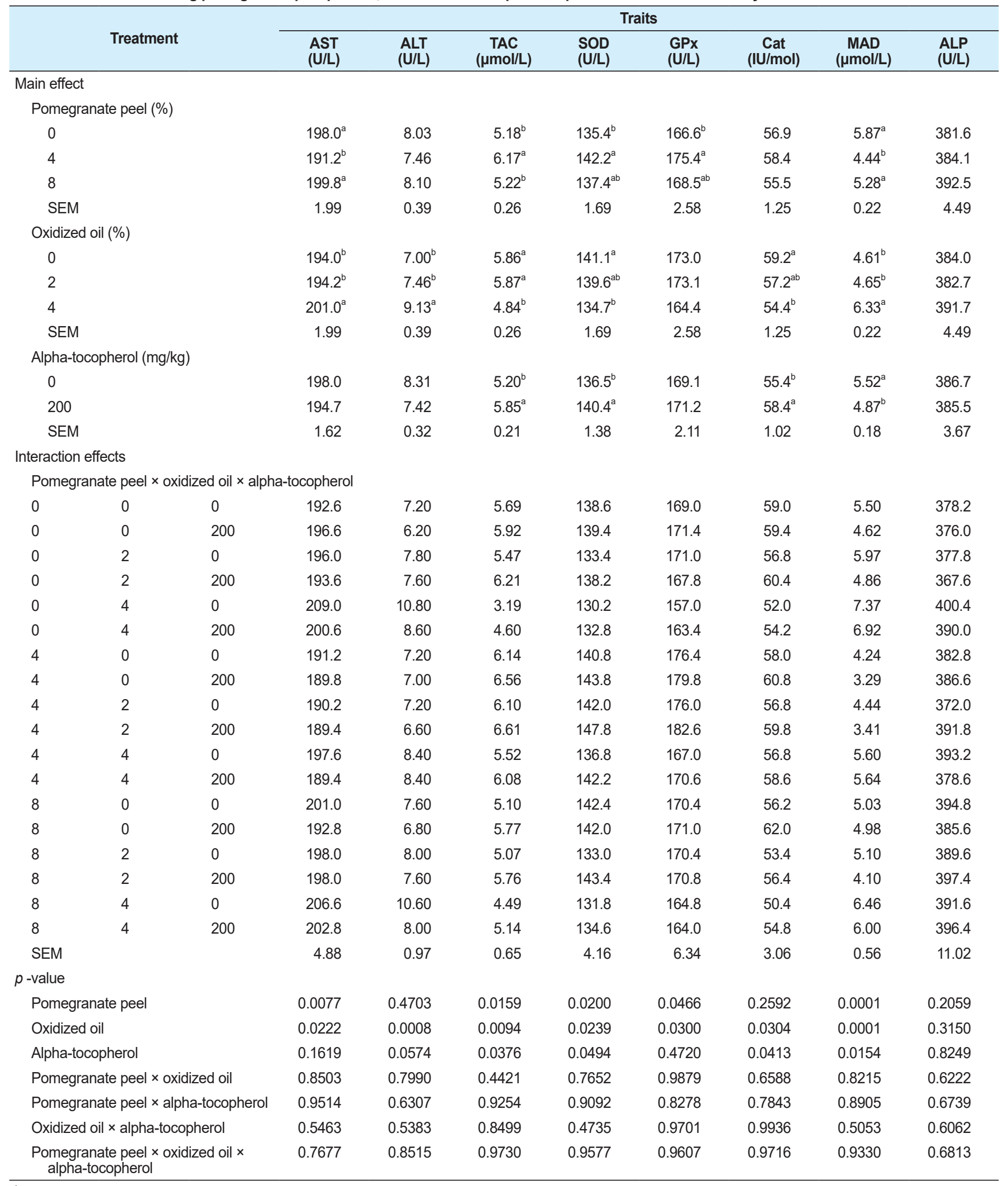

\footnotetext{
${ }^{a, b}$ Means in columns with same superscript do not differ significantly $p<0.05$.

AST, aspartate transaminase; ALT, alanine transaminase; TAC, total antioxidant capacity; SOD, superoxide dismutase; GPx, glutathione peroxidase; Cat, catalase; MDA, malondialdehyde; ALP, alkaline phosphatase.
} 
Table 7. Relationship of pomegranate peel, oxidized oil and alpha-tocopherol and blood enzymes of broiler chickens

\begin{tabular}{|c|c|c|c|}
\hline Traits & Regression & $R^{2}$ & Equation \\
\hline \multicolumn{4}{|l|}{ Pomegranate peel } \\
\hline AST (U/L) & ns & & \\
\hline $\mathrm{ALT}(\mathrm{U} / \mathrm{L})$ & ns & & \\
\hline $\mathrm{TAC}(\mu \mathrm{mol} / \mathrm{L})$ & ns & & \\
\hline $\mathrm{SOD}(\mathrm{U} / \mathrm{L})$ & ns & & \\
\hline GPx (U/L) & ns & & \\
\hline Cat (IU/moL) & ns & & \\
\hline $\operatorname{MAD}(\mu \mathrm{mol} / \mathrm{L})$ & ns & & \\
\hline $\operatorname{ALP}(\mathrm{U} / \mathrm{L})$ & ns & & \\
\hline \multicolumn{4}{|l|}{ Oxidized oil } \\
\hline AST (U/L) & $L<0.0158$ & 0.08 & $y=194.00-1.550 x$ \\
\hline $\mathrm{ALT}(\mathrm{U} / \mathrm{L})$ & $L<0.0002$ & 0.16 & $y=7.00-0.0666 x$ \\
\hline $\mathrm{TAC}(\mu \mathrm{mol} / \mathrm{L})$ & $L<0.0088$ & 0.09 & $y=5.86+0.2610 x$ \\
\hline $\mathrm{SOD}(\mathrm{U} / \mathrm{L})$ & $L<0.0092$ & 0.08 & $y=144.16+0.075 x$ \\
\hline GPx (U/L) & $L<0.0170$ & 0.08 & $y=173.00+2.233 x$ \\
\hline Cat $(\mathrm{IU} / \mathrm{mol})$ & $L<0.0069$ & 0.08 & $y=59.23-0.7750 x$ \\
\hline $\mathrm{MAD}(\mu \mathrm{mol} / \mathrm{L})$ & $Q<0.0079$ & 0.26 & $y=4.61-0.3975 x+0.2062 x^{2}$ \\
\hline $\operatorname{ALP}(\mathrm{U} / \mathrm{L})$ & ns & & \\
\hline \multicolumn{4}{|l|}{ Alpha-tocopherol } \\
\hline AST (U/L) & ns & & \\
\hline $\mathrm{ALT}(\mathrm{U} / \mathrm{L})$ & ns & & \\
\hline $\mathrm{TAC}(\mu \mathrm{mol} / \mathrm{L})$ & $L<0.0450$ & 0.04 & $y=5.20+0.0032 x$ \\
\hline $\mathrm{SOD}(\mathrm{U} / \mathrm{L})$ & ns & & \\
\hline GPx (U/L) & ns & & \\
\hline Cat $(\mathrm{IU} / \mathrm{mol})$ & $L<0.0379$ & 0.04 & $y=55.48+0.0150 x$ \\
\hline MAD ( $\mu \mathrm{mol} / \mathrm{L})$ & $L<0.0465$ & 0.04 & $y=5.52-0.0032 x$ \\
\hline ALP (U/L) & ns & & \\
\hline
\end{tabular}

$\mathrm{L}$, Linear regression $p$-value; $\mathrm{Q}$, Quadratic regression $p$-value; Number of replication $=5$.

AST, aspartate transaminase; ALT, alanine transaminase; TAC, total antioxidant capacity; SOD, superoxide dismutase; GPx, glutathione peroxidase; Cat, catalase; MDA, malondialdehyde; ALP, alkaline phosphatase.

in the concentration of SOD in the serum of broilers fed pomegranate peel. In addition, Saleh et al. [21] noted that broilers fed the pomegranate peel diet had higher serum SOD and GPx concentrations than those fed the low-level pomegranate peel powder, although the development rate was not statistically significant. The high concentration of SOD and CAT in the body leads to improved protection of cell membranes against oxidative stress and ROS [40]. Pomegranate peel contains phenolic and antioxidant compounds [10], which may improve the antioxidant status of broilers by increasing antioxidant enzyme activity [2,42]. Verma et al. [43] reported that herbal products include antioxidant compounds that directly inhibit lipid oxidation in tissues. Antioxidant enzymes can neutralize the free radicals of different types of oxygen. Hence, the use of pomegranate by-products in diets reduces protein and DNA damage in the body, which probably prevents the production of oxygen free radicals in broilers [44].

The phenolic compounds of herbal products directly cleanse free radical species and improve the cell's other defense systems, which activate antioxidant enzymes such as SOD and CAT in the body and increase antioxidant defense. Generally, it has been suggested that hepatic antioxidant enzymes 
such as SOD and CAT play an important role in oxidative stress protection, and these enzymes catalytically scavenge ROS in tissue, thereby increasing endogenous health mechanisms [45].

In our investigation, dietary supplementation with $4 \%$ pomegranate peel powder resulted in lower MDA concentrations compared with other groups, which is in agreement with earlier studies in birds $[21,36]$. A previous study demonstrated that serum MDA concentration was reduced in response to antioxidant products in broilers [2]. It has been shown that with enhanced serum SOD and GPx activity, serum MDA concentration was reduced by supplementation of antioxidant compounds into broiler diets [46].

Dietary oxidized oil resulted in higher AST and ALT concentrations in this study, in agreement with Ghasemi-Sadabadi et al. [2], who demonstrated that the addition of $4 \%$ high peroxide value soybean oil in broiler diets raised the serum AST and ALT concentrations. Furthermore, dietary intake of $4 \%$ oxidized oil has been reported to increase oxidative stress in the body [5]. Oxidative stress can affect liver function because higher oxidative stress causes an imbalance between the defense mechanism of the body and ROS production, which increases the serum AST and ALT concentrations in broilers. Similarly, Hori et al. [47] reported damaged liver tissue in rats exposed to high oxidative stress. They also showed that higher oxidative stress increased the AST and ALT concentrations. Higher AST and ALT concentrations are associated with hepatic or muscular disorders of the liver [48].

The results showed that broilers fed with $4 \%$ oxidized oil had lower serum TAC, SOD, and CAT than the other groups. However, the group that received $4 \%$ oxidized oil showed increased serum MDA concentration compared to the other groups. The results of various studies have confirmed that oxidized dietary oils reduce the concentrations of serum antioxidants and increase serum MDA concentrations [37,49]. Consistent with the conclusions of previous investigations [7], oxidized oil reduced the activity of blood antioxidant enzymes. Delles et al. [49] observed that the inclusion of highly oxidized oil in broiler diets reduced SOD, CAT, and GPx activity. It seems that the lower antioxidant enzyme activity in this study was due to oxidative stress. In addition, the researchers noted that enzyme activity in the body is associated with stress intensity [50]. Hence, lower antioxidant concentrations in the serum may be directly related to oxidative stress, which is produced by high amounts of oxidized oil [51]. MDA is the second principal lipid oxidation marker that is under the impression of lipid peroxidation and oxidative stress in the body. Similarly, the high serum MDA concentration in broilers fed oxidized oil can be associated with free radicals of lipid peroxidation in birds [7]. Moreover, the researcher demonstrated that the serum MDA concentration was significantly increased by using high peroxide value oil in mice [37].

In the present study, supplementation of $200 \mathrm{mg} / \mathrm{kg}$ alpha-tocopherol in diets increased the serum TAC, SOD, and CAT concentrations in broilers. Broilers fed with diets containing alphatocopherol were identified by their higher blood antioxidant enzyme concentrations [52]. Alphatocopherol is a fat-soluble vitamin, which is commonly appreciated for its ability to prevent free radicals and defend cell membranes from oxidation [53]. Published experimental data show that alpha-tocopherol improves hepatic antioxidant defenses and reduces lipid peroxidation in the body [52]. Lin et al. [40] showed that the use of $160 \mathrm{mg} / \mathrm{kg}$ alpha-tocopherol increased the SOD concentration in the brain tissue of birds. In addition, these researchers found higher CAT concentrations in the liver tissue. It has been shown that SOD has an essential function of defending cells against damage from oxidative stress, which converts superoxide to $\mathrm{H}_{2} \mathrm{O}_{2}$ and oxygen, while $\mathrm{H}_{2} \mathrm{O}_{2}$ is decreased by CAT and GPx to $\mathrm{H}_{2} \mathrm{O}$ and oxygen. Furthermore, GPx is qualitatively necessary for maintaining low cellular $\mathrm{H}_{2} \mathrm{O}_{2}$ concentrations because this enzyme has a lower $\mathrm{Km}$ than the CAT antioxidant [40]. Inal et al. [54] reported a significant increase in the SOD and CAT concentrations by oral alpha-tocopherol therapy ( $200 \mathrm{mg} /$ day). It was apparent that 200 
$\mathrm{mg} / \mathrm{kg}$ of alpha-tocopherol supplementation reduced the serum MDA concentration in this study. In agreement with this finding, the researchers observed that alpha-tocopherol supplementation decreased the MDA concentrations in birds [36,40]. Tekce et al. [55] demonstrated that the supplementation of phenolic compounds (essential oil) in the water had not affected thiobarbituric acid reactive substance (TBARS) values in the broiler. Alpha-tocopherol is the main antioxidant that protects against peroxidation. This vitamin eliminated hydroxyl, alkoxyl, peroxyl, and superoxide anion radicals and improved membrane health [36]. Sahin et al. [56] indicated that supplementation with alpha-tocopherol in diets reduced the serum and liver MDA concentrations in Japanese quails.

\section{Blood biochemical parameters}

The effects of using different level of pomegranate peel powder, oxidized oil and alpha- tocopherol in the diet on blood biochemical parameters in broiler chickens are shown in Tables 8 and 9. Also, linear and quadratic effects of pomegranate peel powder, oxidized oil and alpha-tocopherol and blood biochemical parameters shown in Table 10 .

The serum glucose, total protein, globulin and LDL concentration were significantly affected by feeding pomegranate peel powder in diets $(p<0.05)$, although there was a linear tendency to decrease these blood parameters. Further, the results indicated that the use of $8 \%$ pomegranate peel in diets had significantly lower serum glucose, total protein, and globulin concentration compared to other groups in this study $(p<0.05)$. Also, the addition of $4 \%$ pomegranate peel powder in diet reduced LDL concentration than control group. Results showed that serum glucose, triglyceride, cholesterol and LDL concentration had significantly affected by the utilization of oxidized oil in diets $(p<0.05)$. The serum glucose concentration tended to decrease linearly with increasing oxidized oil level in the diet, and also significantly lower serum glucose concentration had shown at $4 \%$ oxidized oil than the control group. The serum triglyceride and cholesterol concentration increased linearly at $4 \%$ oxidized oil treatment. Further, the LDL concentration showed quadric differences among oxidized oil treatment. Results mentioned that the addition of $4 \%$ of oxidized oil in diets significantly had higher blood lipids than other groups $(p<0.05)$. Both cholesterol and LDL concentration results were significantly affected by dietary alpha-tocopherol, hence the supplementation of $200 \mathrm{mg} / \mathrm{kg}$ alpha-tocopherol in the diet significantly decreased serum cholesterol and LDL concentration in broilers $(p<0.05)$. Besides, the supplementation of the alpha-tocopherol in diets had linearly affected the serum LDL concentration in broilers $(p<$ 0.05 ). According to data, an interaction was not found between dietary pomegranate peel powder, oxidized oil, and alpha-tocopherol for the blood biochemical parameters. But, serum cholesterol concentration showed interaction affect between dietary pomegranate peel powder, oxidized oil, and alpha-tocopherol.

In the present study, serum glucose, total protein, and globulin concentrations decreased in response to the high amount of pomegranate peel powder, which is in agreement with the reports of previous studies These experimental results agree with those of Abass et al. [10], who reported a decline in the serum glucose concentration associated with 7.5\% pomegranate peel powder in Japanese quails. Furthermore, Huang et al. [57] reported that supplementation with pomegranate peel extract decreased the blood glucose concentration in rats. A reduction in the blood protein was also found by Abdel Baset et al. [39], where the serum total protein concentration in the broilers decreased with $4 \mathrm{~g}$ of pomegranate peel powder. In contrast with our findings, Abass et al. [10] reported an improvement in the serum total protein concentration when using pomegranate peel powder in quail diets. Furthermore, it has been shown that pomegranate peel contains a high amount of $\mathrm{CF}$ and tannins, which may reduce gastrointestinal absorption and consequently 
Table 8. The effects of using pomegranate peel powder, oxidized oil and alpha-tocopherol in diets on blood biochemical parameters in broiler chickens

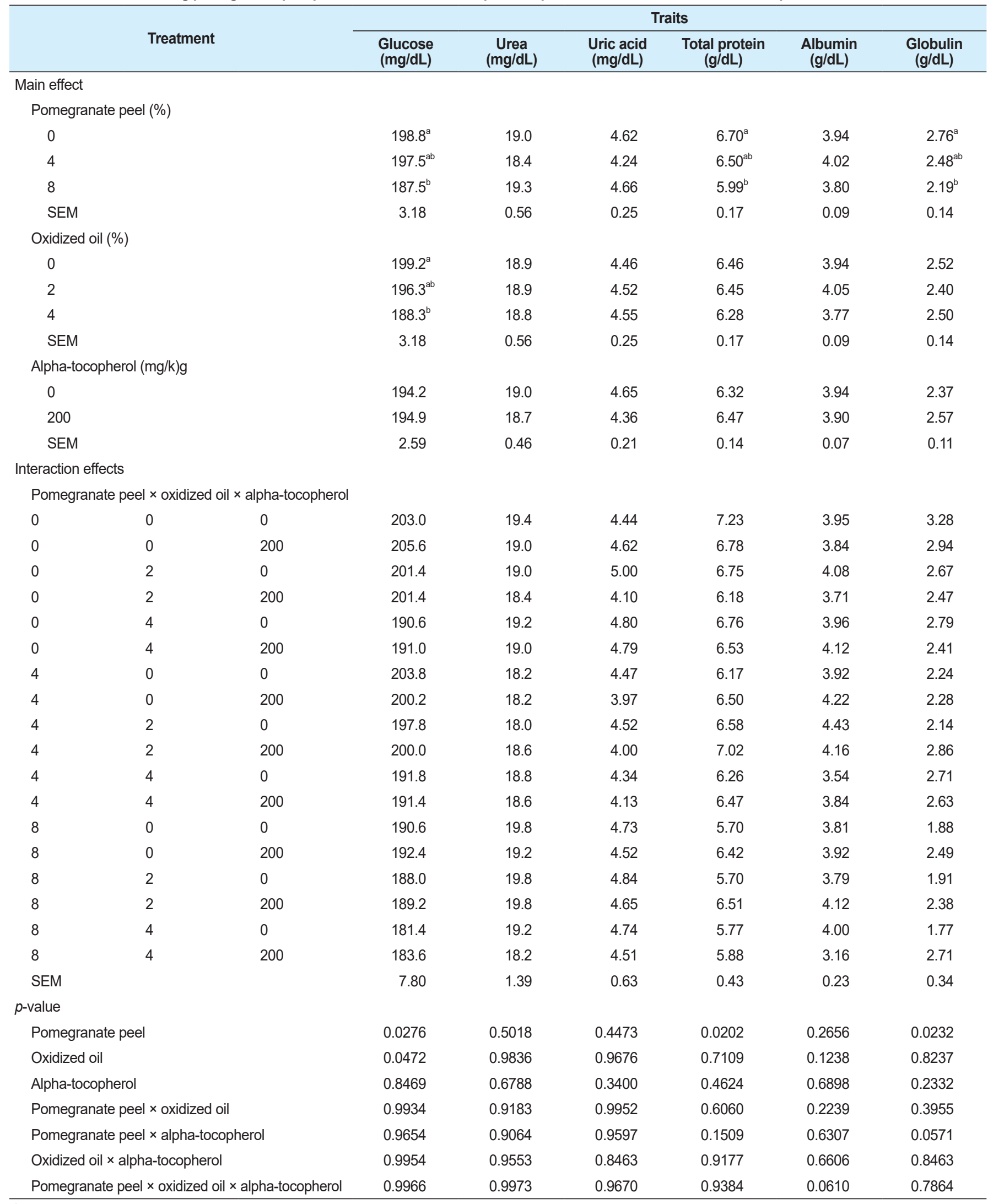

a,b Means in columns with same superscript do not differ significantly $p<0.05$. 
Table 9. The effects of using pomegranate peel powder, oxidized oil and alpha-tocopherol in diets on blood lipids in broiler chickens

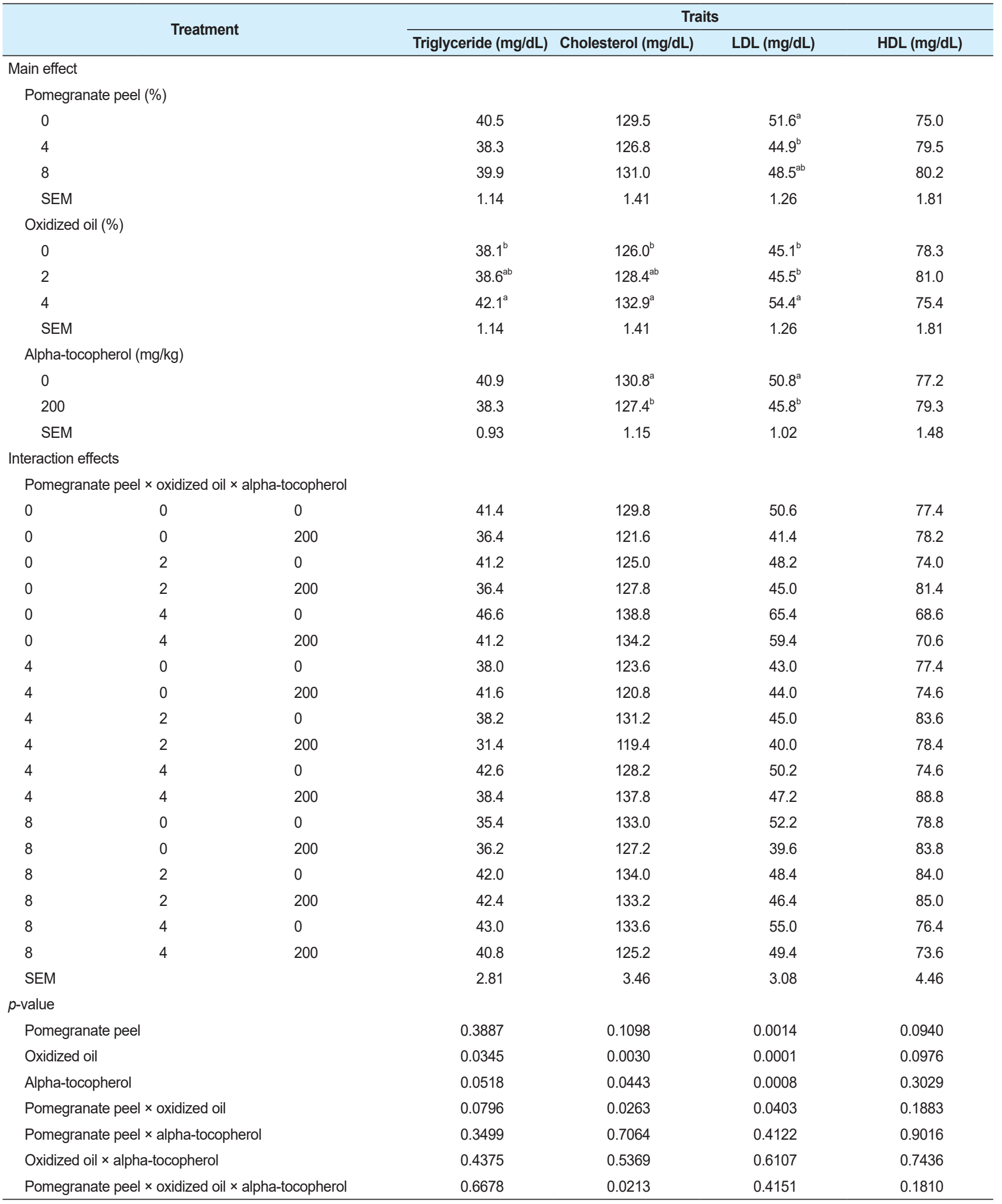

${ }^{a, b}$ Means in columns with same superscript do not differ significantly $p<0.05$.

LDL, low-density lipoprotein; HDL, high-density lipoprotein. 
Table 10. Relationship of pomegranate peel, oxidized oil and alpha-tocopherol and blood biochemical parameters of broiler chickens

\begin{tabular}{|c|c|c|c|}
\hline Traits & Regression & $R^{2}$ & Equation \\
\hline \multicolumn{4}{|l|}{ Pomegranate peel } \\
\hline Glucose (mg/dL) & $L<0.0098$ & 0.08 & $y=198.83+0.7458 x$ \\
\hline Urea (mg/dL) & ns & & \\
\hline Uric acid (mg/dL) & ns & & \\
\hline Total protein (g/dL) & $L<0.0048$ & 0.09 & $y=6.70-0.0142 x$ \\
\hline Albumin (g/dL) & ns & & \\
\hline Globulin (g/dL) & $L<0.0057$ & 0.08 & $y=2.76-0.0699 x$ \\
\hline Triglyceride (mg/dL) & ns & & \\
\hline Cholesterol (mg/dL) & ns & & \\
\hline LDL (mg/dL) & ns & & \\
\hline HDL (mg/dL) & ns & & \\
\hline \multicolumn{4}{|l|}{ Oxidized oil } \\
\hline Glucose (mg/dL) & $\mathrm{L}<0.0127$ & 0.07 & $y=199.26-0.2250 x$ \\
\hline Urea (mg/dL) & ns & & \\
\hline Uric acid (mg/dL) & ns & & \\
\hline Total protein (g/dL) & ns & & \\
\hline Albumin (g/dL) & ns & & \\
\hline Globulin (g/dL) & ns & & \\
\hline Triglyceride (mg/dL) & $L<0.0212$ & 0.07 & $y=38.16-0.5500 x$ \\
\hline Cholesterol (mg/dL) & $L<0.0022$ & 0.10 & $y=126.00+0.6916 x$ \\
\hline $\mathrm{LDL}(\mathrm{mg} / \mathrm{dL})$ & $Q<0.0183$ & 0.23 & $y=45.13-1.9583 x+1.07 x^{2}$ \\
\hline $\mathrm{HDL}(\mathrm{mg} / \mathrm{dL})$ & ns & & \\
\hline \multicolumn{4}{|l|}{ Alpha-tocopherol } \\
\hline Glucose (mg/dL) & ns & & \\
\hline Urea (mg/dL) & ns & & \\
\hline Uric acid (mg/dL) & ns & & \\
\hline Total protein (g/dL) & ns & & \\
\hline Albumin (g/dL) & ns & & \\
\hline Globulin (g/dL) & ns & & \\
\hline Triglyceride (mg/dL) & ns & & \\
\hline Cholesterol (mg/dL) & ns & & \\
\hline LDL (mg/dL) & $L<0.0068$ & 0.08 & $y=50.88-0.0253 x$ \\
\hline $\mathrm{HDL}(\mathrm{mg} / \mathrm{dL})$ & ns & & \\
\hline
\end{tabular}

L, Linear regression $p$-value; $\mathrm{Q}$, Quadratic regression $p$-value.

Number of replication $=5$.

LDL, low-density lipoprotein; HDL, high-density lipoprotein.

diminish food intake [58]. It seems that low gastrointestinal absorption reduced blood metabolites, such as glucose and blood protein, in this experiment. According to previous research, the physiological and biochemical systems are changed by tannins [59]. Therefore, these compounds obtained from pomegranate peel have a negative effect on nitrogen balance, intestinal absorption of sugars and amino acids, and protein catabolism [60]. It has also been previously stated that tannins cause major changes in protein bioavailability in the body, which may decrease blood protein concentrations.

By examining the results, it can be concluded that the replacement of $4 \%$ pomegranate peel 
powder in the grower and finisher diets reduced the serum LDL concentration of broilers at 42 days of age. These outcomes are in agreement with earlier investigations reporting that the addition of pomegranate peel to diets decreased blood lipid concentrations in broilers [10,61]. Similarly, serum lipids decreased in broilers fed with a diet containing $7.5 \%$ of pomegranate peel powder Abbas et al. [10]. It is generally accepted that the phenolic compounds of pomegranate peel, such as punicalagin, punicalin, gallic acid, and elegiac acid, may affect serum lipid concentrations and other blood metabolites [62]. Furthermore, pomegranate peel contains powerful antioxidants that play an important role in the oxidation of lipids in the body [10]. Phenolic compounds protect serum lipids against oxidation [63]. In addition, pomegranate peel may accelerate cholesterol metabolism by modifying cholesterol transport via HDL; therefore, it reduces serum cholesterol and LDL concentrations in the blood [33]. Similarly, the researcher suggested that pomegranate peels had hypocholesterolemic and hypolipidemic impacts. They also state that pomegranate peel hindered lipid digestion, absorption, and metabolism [61]. It is similar to a high-fat diet with gallic acid supplementation, as phenolic compounds reduced triglyceride concentrations [64]. The low serum lipid concentrations in this study may be associated with active phenolic compounds in pomegranate peel powder, which have an inhibitory effect on pancreatic lipase activity inhibits fat absorption from the intestinal tract, and reduces fat aggregation in lipoid tissues $[8,65]$. Bayraktar et al. [66] indicated that the essential fatty acid mixture application was found to have no effect on the serum levels of very low-density lipoprotein (VLDL), glucose, total bilirubin, and TG in broilers.

In the current study, the serum glucose concentration decreased with the addition of $4 \%$ oxidized oil to the diet, which is in agreement with the reports of earlier studies performed on birds. Ghasemi-Sadabadi et al. [2] and Tavárez et al. [38] reported that the feeding of high peroxide value oil decreased serum glucose concentration in birds. Besides, Ghasemi-Sadabadi et al. [2] reported that the addition of $4 \%$ oxidized oil with $45.18,101.99$, and $146.03 \mathrm{meq} / \mathrm{kg}$ peroxide values in the diets reduced the serum glucose concentration than fresh oil. It seems that the low serum glucose concentration observed in this study may be associated with oxidative stress. Thus, the use of oxidized oil raises ROS counts, which react with proteins, lipids, and fat-soluble vitamins that reduce the nutrient value of food [38]. In addition, researchers have shown that the use of oxidized oil in diets has deleterious effects on body metabolism in birds [2]. In contrast, Açıkgöz et al. [27] observed no differences in blood glucose concentrations after the treatments when broilers were fed oxidized oil during the experiment. These differences in the reports of the studies may be attributed to the various concentrations of oxidized oil in diets and different peroxide values of oil [2].

The results demonstrated that by utilizing $4 \%$ oxidized oil in diets, the serum triglyceride, cholesterol, and LDL concentrations of broilers increased at the end of the experimental period. These conclusions are consistent with other experimental results, in which oxidized oil supplementation increased serum triglyceride, cholesterol, and LDL concentrations [67]. These results match those of Khan-Merchant et al. [67], who confirmed that oxidized oil enhanced serum cholesterol, triglyceride, LDL concentrations, and the rate of atherosclerosis. Kishawy et al. [8] reported that the inclusion of oxidized oil in broiler diets increased cholesterol, triglyceride, and LDL concentrations. In general, the increase in serum lipid concentration in broilers fed with oxidized oil was expected because oxidized oil increased oxidative stress in birds, which is directly related to the higher serum lipid concentrations [67]. It seems that the higher plasma triglyceride concentration is a consequence of the lower availability of polyunsaturated fatty acids (PUFAs). Furthermore, the increase in serum cholesterol concentration can reduce the liver uptake of cholesterol [27].

The results showed that supplementation with $200 \mathrm{mg} / \mathrm{kg}$ alpha-tocopherol in the diet decreased the serum cholesterol and LDL concentrations in broilers at 42 days of age. These findings are in 
agreement with those of previous studies reporting that alpha-tocopherol supplementation reduced cholesterol and LDL concentrations in broilers [68]. Similarly, Sahin et al. [56] discovered that alpha-tocopherol supplementation reduced blood cholesterol concentrations in Japanese quails under heat stress. Arslan et al. [68] concluded that raising the concentrations of alpha-tocopherol decreased the serum cholesterol concentration, but this reduction was not statistically significant. In addition, Franchini et al. [69] stated that the inclusion of 325 ppm alpha-tocopherol decreased serum cholesterol and triglyceride concentrations in broilers. Previous studies have demonstrated that the cholesterol concentration was low in turkeys by using alpha-tocopherol supplementation [69]. The addition of alpha-tocopherol to diets prevented atherosclerosis in poultry. However, they reported that the serum cholesterol concentration was not affected by alpha-tocopherol [70].

\section{Hematology parameters}

The effects of using different level of pomegranate peel powder, waste vegetable oil and alphatocopherol in the diet on blood hematology in broiler chickens are shown in Table 11. Also, linear and quadratic effects of pomegranate peel powder, waste vegetable oil and alpha-tocopherol and blood hematology shown in Table 12 .

The results showed that the RBC, Hemoglobin $(\mathrm{Hb})$ and $\mathrm{PCV}$ were affected by dietary pomegranate peel powder $(p<0.05)$. The highest value of $\mathrm{RBC}, \mathrm{Hb}$ and $\mathrm{PCV}$ was observed for a broiler on the $8 \%$ pomegranate peel powder diet on $\mathrm{d} 42$. According to results the blood $\mathrm{Hb}$ and PCV linearly affected with pomegranate peel powder in this experiment. In addition, the data indicated that other hematological traits were unaffected by pomegranate peel, oxidized oil, and alpha-tocopherol in this study. In this experiment, the RBC, $\mathrm{Hb}$, and PCV concentrations were lower in broilers fed with $8 \%$ pomegranate peel powder than in the other groups. Despite the effects of dietary pomegranate peel on bird hematology, few researchers have discussed them. However, $\mathrm{Wu}$ et al. [71] showed that supplementation with pomegranate peel reduced RBC counts in mice. The decrease in RBCs has a dangerous impact on the performance of the tissue. Hemoglobin is the main protein that carries oxygen in RBCs, and some studies have shown that it plays an important role in innate immune responses [71]. Disparities in the $\mathrm{RBC}, \mathrm{Hb}$, and PCV responses of broilers, when included with a high amount of pomegranate peel, could be associated with higher tannin concentrations in the basal diet $[65,72]$. The decrease in RBCs has a dangerous impact on the performance of the tissue. Hemoglobin is the main protein that carries oxygen in RBCs, and some studies have reported that it plays an important role in innate immune responses. It has been noted that polyphenol compounds can bind metals such as iron and made chelate [73]. Iron is an essential element of the body, and tannins are antinutritional factors that contribute to the lack of iron [72]. Therefore, it seems that polyphenolic sources such as tannic acid in pomegranate peel could decrease the bioavailability of iron elements [74]. Lee et al. [65] indicated that the consumption of 125, 250, 500 , or $1,000 \mathrm{mg}$ tannic acid $/ \mathrm{kg}$ in feed reduced serum iron concentrations, as well as erythrocyte, hemoglobin, and hematocrit. It has been indicated that polyphenolic hydroxyl combinations are present as oxygen anions and can react with metal ions [72]. Researchers have reported that tannic acid reduces iron bioavailability and iron status in animal models [72]. The reduced RBC, $\mathrm{Hb}$, and PCV in high pomegranate peel powder groups may be associated with the ant nutrient properties of tannins, which can contribute to the reduction of iron [65,72]. In general, the decline in $\mathrm{RBC}, \mathrm{Hb}$, and $\mathrm{PCV}$ in the broiler chickens was dependent on a high dietary pomegranate peel concentration. In contrast with our results, Pertiwi [75] reported that hydrolyzable tannins develop RBC counts per unit of blood. Also, Bayraktar and Tekce [76] found that adding essential Oil in the water had not shown a significant difference between the groups WBC, RBC, Hemoglobin (HGB), Hematocrit (HCT). The results of this study revealed that oxidized oil and alpha- 
Table 11. The effects of using pomegranate peel powder, oxidized oil and alpha-tocopherol in diets on blood hematological parameters in broiler chickens

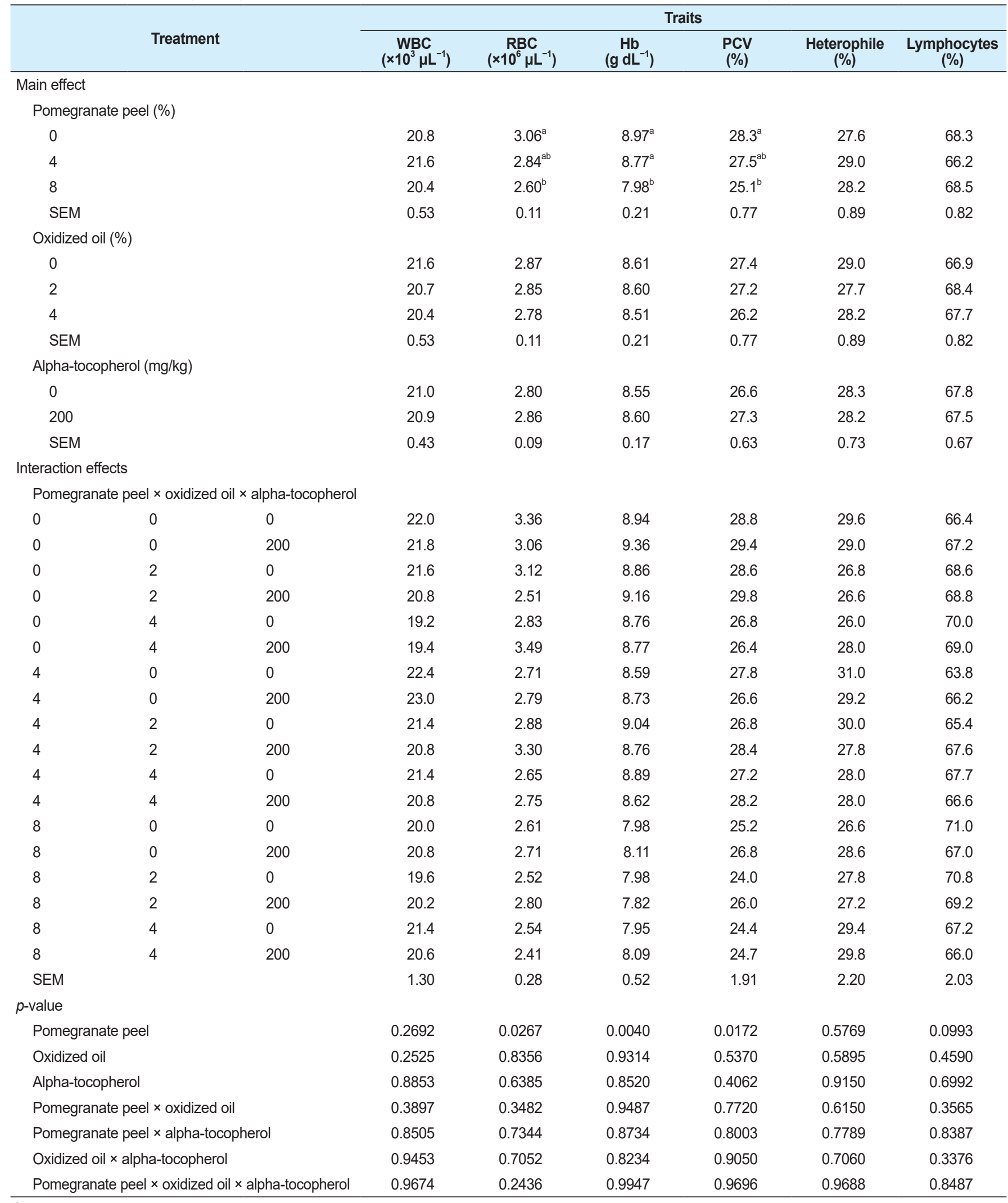

$\overline{a, b}$ Means in columns with same superscript do not differ significantly $p<0.05$.

WBC, white blood cell; RBC, red blood cell; $\mathrm{Hb}$, hemoglobin; $\mathrm{PCV}$, packed cell volume. 
Table 12. Relationship of pomegranate peel, oxidized oil and alpha-tocopherol and blood hematological parameters of broiler chickens

\begin{tabular}{|c|c|c|c|}
\hline Traits & Regression & $R^{2}$ & Equation \\
\hline \multicolumn{4}{|l|}{ Pomegranate peel } \\
\hline WBC $\left(\times 10^{3} \mu L^{-1}\right)$ & ns & & \\
\hline $\operatorname{RBC}\left(\times 10^{6} \mu \mathrm{L}^{-1}\right)$ & ns & & \\
\hline $\mathrm{Hb}\left(\mathrm{g} \mathrm{dL}^{-1}\right)$ & $L<0.0006$ & 0.13 & $y=8.97+0.0221 x$ \\
\hline PCV (\%) & $L<0.0036$ & 0.10 & $y=28.30-0.0125 x$ \\
\hline Heterophile (\%) & ns & & \\
\hline Lymphocytes (\%) & ns & & \\
\hline \multicolumn{4}{|l|}{ Oxidized oil } \\
\hline WBC $\left(\times 10^{3} \mu \mathrm{L}^{-1}\right)$ & ns & & \\
\hline $\operatorname{RBC}\left(\times 10^{6} \mu \mathrm{L}^{-1}\right)$ & ns & & \\
\hline $\mathrm{Hb}\left(\mathrm{g} \mathrm{dL}^{-1}\right)$ & ns & & \\
\hline PCV (\%) & ns & & \\
\hline Heterophile (\%) & ns & & \\
\hline Lymphocytes (\%) & ns & & \\
\hline \multicolumn{4}{|l|}{ Alpha-tocopherol } \\
\hline WBC $\left(\times 10^{3} \mu L^{-1}\right)$ & ns & & \\
\hline $\operatorname{RBC}\left(\times 10^{6} \mu \mathrm{L}^{-1}\right)$ & ns & & \\
\hline $\mathrm{Hb}\left(\mathrm{g} \mathrm{dL}^{-1}\right)$ & ns & & \\
\hline PCV (\%) & ns & & \\
\hline Heterophile (\%) & ns & & \\
\hline Lymphocytes (\%) & ns & & \\
\hline
\end{tabular}

L, linear regression $p$-value.

Number of replication $=5$.

WBC, white blood cell; RBC, red blood cell; Hb, hemoglobin; PCV, pack cell volume.

tocopherol inclusion in the diet did not affect broiler hematology because none of the data were influenced by oxidized oil and alpha-tocopherol. The results of this experiment revealed that the addition of pomegranate peel powder to the diet did not affect broiler hematology because none of the data were influenced by treatments. Similar to our results, the researcher showed that supplementation with pomegranate peel did not influence immune parameters [74]. However, recent studies have demonstrated that tannins and phenolic compounds of pomegranate peel also have an immunomodulatory capacity by stimulating lymphocyte growth [77].

By analyzing the results, it can be concluded that the inclusion of different concentrations of oxidized oil in broiler diets did not significantly affect WBC counts at the end of the study. The results of this research were not in agreement with the findings of some authors [78] that show that immune cells decrease with the supplementation of peroxidation. These differences between research reports may be associated with the differences in the concentrations used or peroxide value in oil. Based on the results obtained from this study, it was observed that the birds receiving vitamin $\mathrm{E}$ treatment did not show significant effects on hematological parameters at the end of the experiment. In contrast, supplementation of $\alpha$-tocopherol has been shown to have beneficial effects on the immune response of broilers. [26].

\section{Antibody titer against sheep red blood cell}

The effects of using different levels of pomegranate peel powder, waste vegetable oil, and vitamin $\mathrm{E}$ in the diet on antibody titer in broiler chickens are shown in Table 13. Also, linear and quadratic 
effects of pomegranate peel powder, waste vegetable oil and vitamin $\mathrm{E}$ and antibody titer shown in Table 14.

The results of this study demonstrated that the use of pomegranate peel powder in the diet had significantly affected the IgG, IgM, and total immunoglobulin contents $(p<0.05)$. The applied 4\% pomegranate peel powder improve the immunoglobulin contents of broiler chickens compared other groups $(p<0.05)$. Broilers whose diets were used with $8 \%$ pomegranate peel powder had lower IgG, IgM, and total immunoglobulin contents than others $(p<0.05)$. At $42 \mathrm{~d}$ of age, significant differences in $\mathrm{IgG}$, IgM, and total immunoglobulin were found between groups receiving oxidized oil $(p<0.05)$. The addition of $4 \%$ oxidized oil to diets led to a decrease in $\mathrm{IgG}$, IgM, and total immunoglobulin in comparison with the remaining groups $(p<0.05)$. IgG contents decreased linearly with increasing oxidized oil levels in diets, but a tendency for a quadratic response to the IgM and total immunoglobulin was observed. The results did not show a clear significant relationship between the alpha-tocopherol and immunoglobulin counts, there were no regressions models that achieved the data particularly great. Additionally, the consequences described that interaction among the main factors did not affect antibody titer. According to the results, the use of $4 \%$ pomegranate peel improved immunoglobulin concentrations. Our findings are in agreement with those of Ross et al. [79], Saeed et al. [80], and Kishawy et al. [61] who indicated that the inclusion of pomegranate by-products in diets improved immunity. Abdel Baset et al. [39] reported that supplementation with $4 \mathrm{~g}$ of pomegranate peel powder/kg diet increased the IgM concentration in broiler chickens. Saleh [41] reported an increase in IgM and IgG concentrations in broilers fed with pomegranate peel. Immunoglobulin, such as IgM, is involved in the humoral immune response and performs an essential function in immune defense [81], and antibodies are the main immunological factors and present necessary evidence of cellular and humoral immunity in the body [38]. As discussed above, the immune proteins IgM and IgG directly influence the immune response of the living body [71]. Researchers have reported that supplementation with phenolic compounds improves blood immunoglobulin concentrations in birds. Hence, the dietary addition of turmeric rhizome powder to broilers significantly improved blood immunoglobulin concentrations [82]. In some cases, Reda et al. [83] indicated that birds fed nano-curcumin increased the concentrations of immunoglobulins and antioxidants compared to the control group. Antioxidant compounds increase the immunoglobulin concentration and immune response through their function in oxidative stress reduction of immune cells [28]. In the present study, it was evident that the immunoglobulin counts were decreased by high oxidized oil concentrations in broilers compared with the other groups. These findings agree with those of Ghasemi-Sadabadi et al. [2], who demonstrated that the use of 101.99 and $146.03 \mathrm{meq} / \mathrm{kg}$ peroxide value in diets decreased IgM and IgG concentration compared to low peroxide value. Similarly, Dibner et al. [84] indicated that oxidized oil decreased the secretion and stability of the intestinal IgA response. Antioxidant and polyphenol compounds, such as pomegranate peel, improved the humoral immunity and cellular immunity of the broilers, which may be associated with ROS scavenging in the body [8]. The researchers stated that the inclusion of oxidized oil in broiler diets reduced the immune response. The low immune response can be due to a low jejunal concentration of secretory immunoglobulin and a high concentration of serum endotoxin $[2,8]$.

\section{Meat quality}

The effects of using different levels of pomegranate peel powder, waste vegetable oil, and vitamin $\mathrm{E}$ in the diet on meat quality in broiler chickens are shown in (Fig. 1). Also, interaction effects of treatments shown in (Fig. 2).

Supplementation of $4 \%$ and $8 \%$ pomegranate peel in diets decreased meat MDA of broilers 
Table 13. The effects of using pomegranate peel powder, oxidized oil and alpha-tocopherol in diets on immunoglobulin in broiler chickens

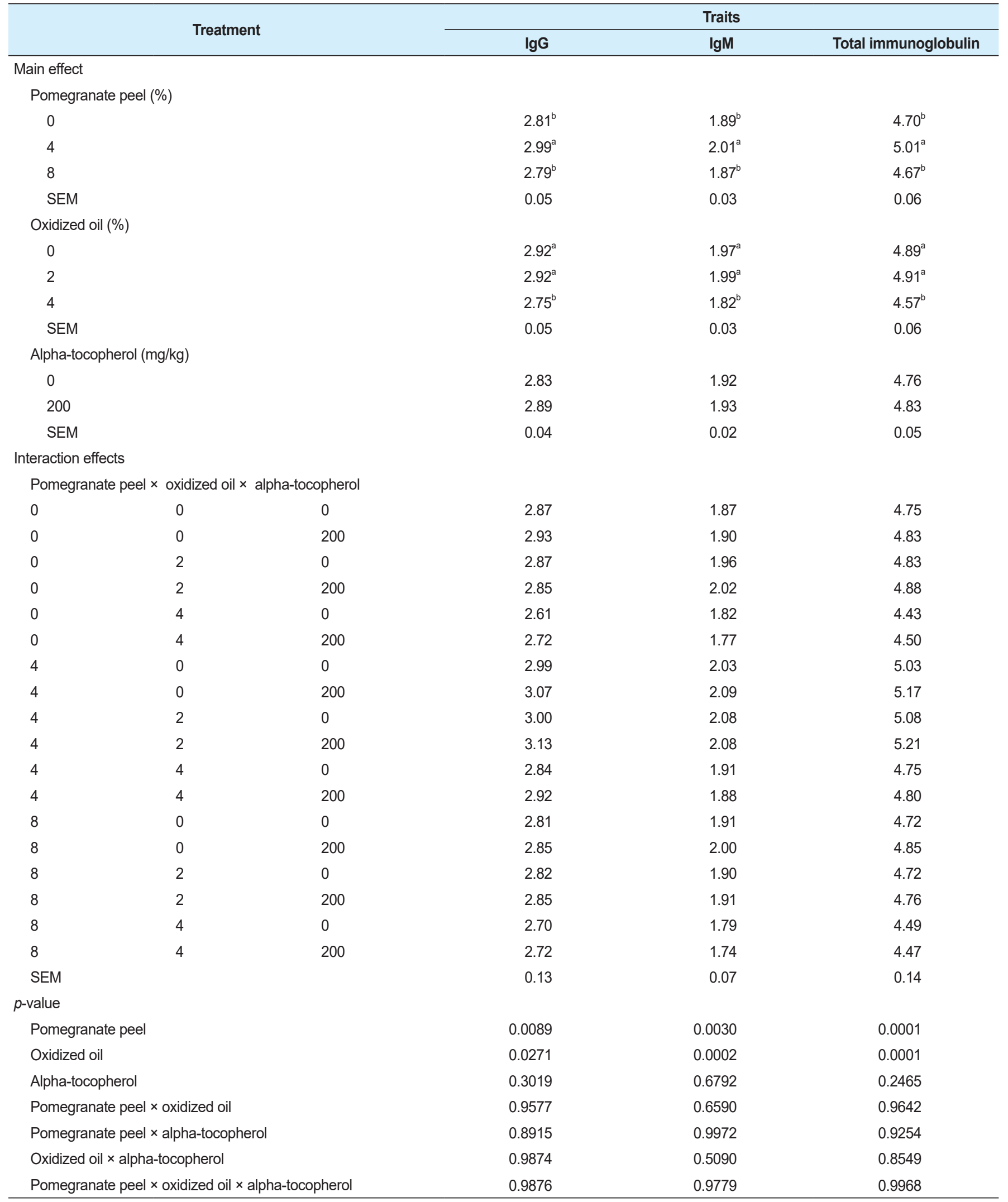

$\overline{a, b}$ Means in columns with same superscript do not differ significantly $p<0.05$.

$\lg$ G, immunoglobulin G; IgM, immunoglobulin M. 
Table 14. Relationship of pomegranate peel, oxidized oil and alpha-tocopherol and immunoglobulin of broiler chickens

\begin{tabular}{lccc}
\hline \multicolumn{1}{c}{ Traits } & Regression & $R^{2}$ & Equation \\
\hline Pomegranate peel & & & \\
IgG & $n s$ & & \\
IgM & $n s$ & & \\
Total immunoglobulin & $n s$ & & \\
Oxidized oil & & & \\
IgG & $\mathrm{L}<0.0166$ & 0.08 & $\mathrm{y}=2.92+0.0394 \mathrm{x}$ \\
IgM & $\mathrm{Q}<0.0086$ & 0.18 & $\mathrm{y}=1.97+0.0617 \mathrm{x}-0.0247 \mathrm{x}^{2}$ \\
Total immunoglobulin & $\mathrm{Q}<0.0127$ & 0.19 & $\mathrm{y}=4.89+0.1011 \mathrm{x}-0.0450 \mathrm{x}^{2}$ \\
Alpha-tocopherol & & & \\
IgG & $\mathrm{ns}$ & & \\
IgM & $\mathrm{ns}$ & & \\
Total immunoglobulin & $\mathrm{ns}$ & & \\
\hline
\end{tabular}

$\mathrm{L}$, linear regression $p$-value; $\mathrm{Q}$, quadratic regression $p$-value. Number of replication $=5$.

IgG, immunoglobulin G; IgM, immunoglobulin M.

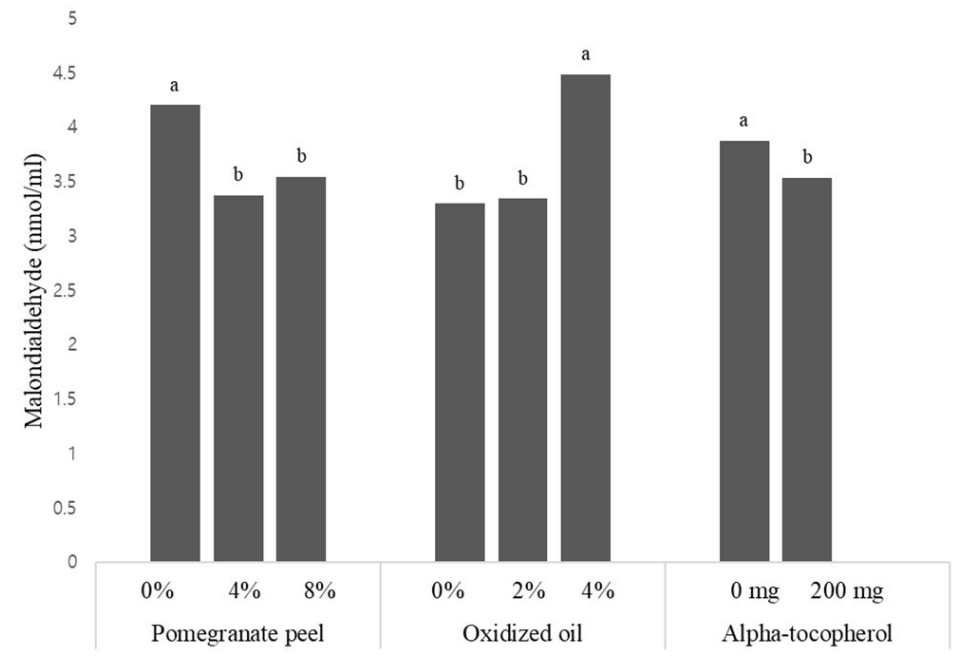

Fig. 1. MDA concentrations of meat in broiler fed pomegranate peel, oxidized oil and alpha-tocopherol (main effect). ${ }^{a, b}$ Means in columns with same superscript do not differ significantly $p<0.05$. MDA, malondialdehyde.

on $\mathrm{d} 42$ compared to the control groups $(p<0.05)$. Dietary inclusion of waste oil had a significant effect on MDA concentration of meat, although the addition of $4 \%$ waste oil in diets increased the meat MDA when compared to the others group $(p<0.05)$. The supplementation of $\alpha$-tocopherol in diets resulted in significantly lower meat MDA $(p<0.05)$. The interaction effects between treatments did not show significant differences in meat quality at the end of the experiment.

The supplementations of pomegranate peel in diets reduced MDA concentration and are in agreement with Saleh et al. [36] and Abdel Baset et al. [39]. It was reported that the inhibitory impact of pomegranate peels on meat oxidation could be due to phenolic compounds such as tannins, which have a strong antioxidant effect on lipid oxidation [39]. The results of this study agree in part with those obtained by Kishawy et al. [61]. Generally, the higher MDA of meat has been previously showed to be positively due to oxidized oil in diets. The oxidized oil resulted in 


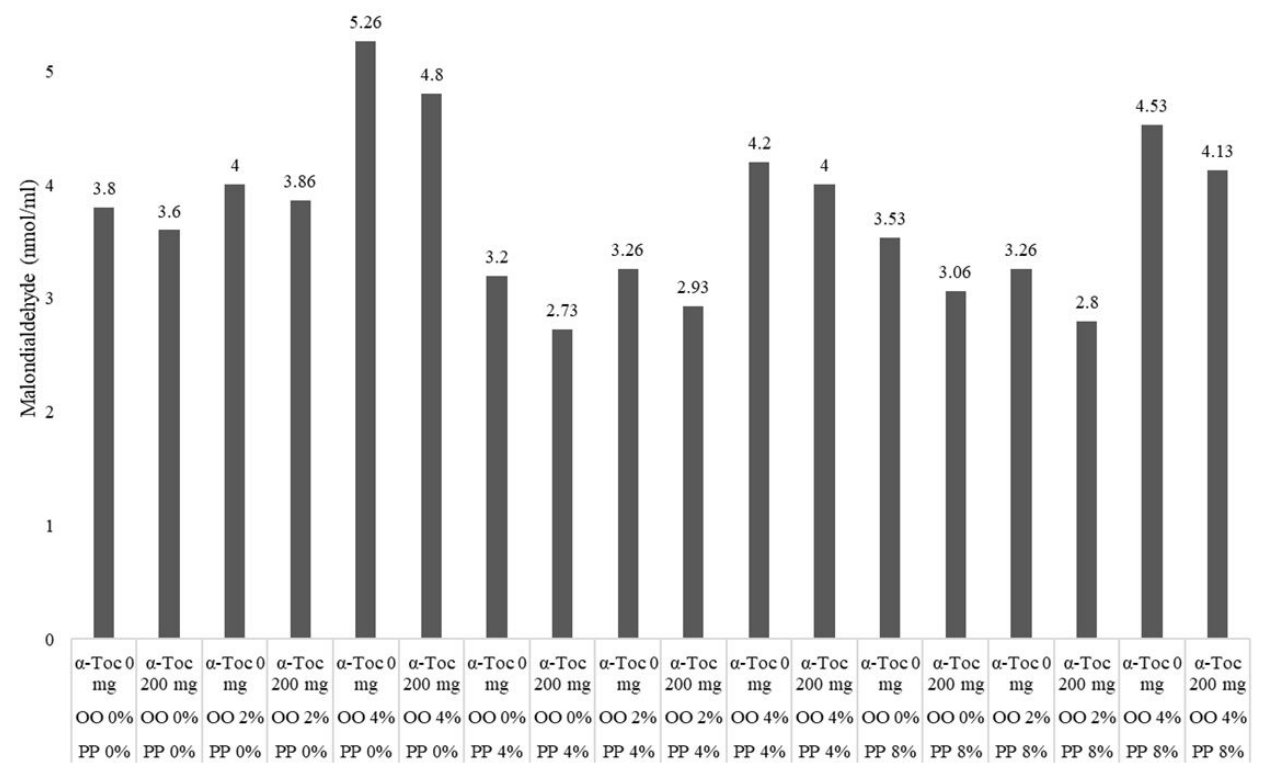

Fig. 2. MDA concentrations of meat in broiler fed pomegranate peel, oxidized oil and alpha-tocopherol (interaction effect). $\alpha$-Toc, $\alpha$-tocopherol; OO, oxidized oil; PP, pomegranate peel; MDA, malondialdehyde.

oxidative damage which decreased the meat quality [2]. The supplementation of $200 \mathrm{mg} / \mathrm{kg}$ alphatocopherol in diets had lower MDA of meat than not-supplemented groups. The MDA of meat can be decreased by alpha-tocopherol in broilers [42]. These researchers also reported an impact of alpha-tocopherol on lipid peroxidation of poultry meat, consequently, MDA was decreased in the muscles by supplementing alpha-tocopherol. The alpha-tocopherol may improve the anti-oxidative activity of broilers by raised antioxidant enzyme activity [42].

\section{REFERENCES}

1. Goñi I, Brenes A, Centeno C, Viveros A, Saura-Calixto F, Rebolé A, et al. Effect of dietary grape pomace and vitamin $\mathrm{E}$ on growth performance, nutrient digestibility, and susceptibility to meat lipid oxidation in chickens. Poult Sci. 2007;86:508-16. https://doi.org/10.1093/ ps $/ 86.3 .508$

2. Ghasemi-Sadabadi M, Veldkamp T, van Krimpen M, Ebrahimnezhad Y, Ghalehkandi JG, Salehi A, et al. Determining tolerance of Japanese quail to different dietary fat peroxidation values by supplementation with rosemary and aloe vera on performance and meat quality. Anim Feed Sci Technol. 2020;267:114574. https://doi.org/10.1016/j.anifeedsci.2020.114574

3. Baião NC, Lara LJC. Oil and fat in broiler nutrition. Braz J Poult Sci. 2005;7:129-41. https:// doi.org/10.1590/S1516-635X2005000300001

4. Chhetri $\mathrm{AB}$, Watts $\mathrm{KC}$, Islam MR. Waste cooking oil as an alternate feedstock for biodiesel production. Energies. 2008;1:3-18. https://doi.org/10.3390/en1010003

5. Mazur-Kuśnirek M, Antoszkiewicz Z, Lipiński K, Kaliniewicz J, Kotlarczyk S. The effect of polyphenols and vitamin $\mathrm{E}$ on the antioxidant status and meat quality of broiler chickens fed low-quality oil. Arch Anim Breed. 2019;62:287-96. https://doi.org/10.5194/aab-62-287-2019

6. Kanner J. Oxidative processes in meat and meat products: quality implications. Meat Sci. 1994;36:169-89. https://doi.org/10.1016/0309-1740(94)90040-X

7. Tan L, Rong D, Yang Y, Zhang B. Effect of oxidized soybean oils on oxidative status and 
intestinal barrier function in broiler chickens. Braz J Poult Sci. 2018;20:333-42. https://doi. org/10.1590/1806-9061-2017-0610

8. Kishawy AT, Omar AE, Gomaa AM. Growth performance and immunity of broilers fed rancid oil diets that supplemented with pomegranate peel extract and sage oil. J Vet Res. 2016;64:S31-8.

9. Yilmaz Y, Toledo RT. Major flavonoids in grape seeds and skins: antioxidant capacity of catechin, epicatechin, and gallic acid. J Agric Food Chem. 2004;52:255-60. https://doi. org $/ 10.1021 / \mathrm{jf0} 0117 \mathrm{~h}$

10. Abbas RJ, Al-Salhie KCK, Al-Hummod SKM. The effect of using different levels of pomegranate (Punica granatum) peel powder on productive and physiological performance of Japanese quail (Coturnix coturnix japonica). Livest Res Rural Dev. 2017;29:231.

11. Santhini E, Ramji B, Viswanadha Vijaya P. Gallic acid isolated from pomegranate peel extract induces reactive oxygen species mediated apoptosis in A549 cell line. J Cancer Ther. 2011;2:16582. http://doi.org/10.4236/jct.2011.25085

12. Panichayupakaranant $P$, Tewtrakul S, Yuenyongsawad S. Antibacterial, anti-inflammatory and anti-allergic activities of standardised pomegranate rind extract. Food Chem. 2010;123:400-3. https://doi.org/10.1016/j.foodchem.2010.04.054

13. Hossin FLA. Effect of pomegranate (Punica granatum) peels and it's extract on obese hypercholesterolemic rats. Pak J Nutr. 2009;8:1251-7. https://doi.org/10.3923/pjn.2009.1251.1257

14. Madrigal-Carballo S, Rodriguez G, Krueger CG, Dreher M, Reed JD. Pomegranate (Punica granatum) supplements: authenticity, antioxidant and polyphenol composition. J Funct Foods. 2009;1:324-9. https://doi.org/10.1016/j.jff.2009.02.005

15. Bravo L, Abia R, Eastwood MA, Saura-Calixtol F. Degradation of polyphenols (catechin and tannic acid) in the rat intestinal tract. Effect on coloic fermentation and faecal output. Br J Nutr. 1994;71:933-46. https://doi.org/10.1079/BJN19940197

16. Brenes A, Viveros A, Goñi I, Centeno C, Saura-Calixto F, Arija I. Effect of grape seed extract on growth performance, protein and polyphenol digestibilities, and antioxidant activity in chickens. Span J Agric Res. 2010:326-33. https://doi.org/10.5424/sjar/2010082-1199

17. Harwood J, Aparicio R. Handbook of olive oil: analysis and properties. Boston, MA: Springer; 2000.

18. Seyedi AH, Janmohamady H, Hosseinkhani A, Shakouri MD. Using complete diet and Sibbald methods to determine the metabolizable energy of 5 Iranian wheat varieties. J Appl Poult Res. 2013;22:388-95. https://doi.org/10.3382/japr.2011-00516

19. AOAC [Association of Official Analytical Chemists] International. Official methods of analysis of AOAC International. 18th ed. Gaithersburg, MD: AOAC International; 2006.

20. Millipore. Liquid chromatographic analysis of amino acids in foods using a modification of the PICO-TAG method. New York, NY: Millipore; 1987.

21. Saleh H, Golian A, Kermanshahi H, Mirakzehi MT. Effects of dietary $\alpha$-tocopherol acetate, pomegranate peel, and pomegranate peel extract on phenolic content, fatty acid composition, and meat quality of broiler chickens. J Appl Anim Res. 2017;45:629-36. https://doi.org/10.108 0/09712119.2016.1248841

22. Sibbald IR. A bioassay for true metabolizable energy in feedingstuffs. Poult Sci. 1976;55:303-8. https://doi.org/10.3382/ps.0550303

23. Ghasemi-Sadabadi M, Ebrahimnezhad Y, Shaddel-Tili A, Bannapour-Ghaffari V, Kozehgari $\mathrm{H}$, Didehvar M. The effects of fermented milk products (kefir and yogurt) and probiotic on performance, carcass characteristics, blood parameters, and gut microbial population in broiler chickens. Arch Anim Breed. 2019;62:361-74. https://doi.org/10.5194/aab-62-361-2019 
24. NRC [National Research Council]. Nutrient requirements of poultry. 9th rev. ed. Washington, DC: The National Academy Press; 1994.

25. Ghasemi-Sadabadi M, Ebrahimnezhad Y, Shaddel-Tili A, Bannapour-Ghaffari V, Saemi Peste-Bigelow S. Comparison of using ionophore and non-ionophore coccidiostats on performance, carcass characteristics, blood biochemical parameters and gut microbial flora in broiler chickens. Iran J Appl Anim Sci. 2019;10:693-704.

26. Mohiti-Asli M, Ghanaatparast-Rashti M. Feeding antioxidant vitamin and vegetable oils to broilers: vitamin $\mathrm{E}$ reduced negative effect of soybean oil on immune response and meat lipid oxidation. Anim Prod Sci. 2018;58:1829-36. https://doi.org/10.1071/AN16677

27. Açıkgöz Z, Bayraktar H, Altan Ö, Akhisaroglu ST, Kırkpınar F, Altun Z. The effects of moderately oxidised dietary oil with or without vitamin $\mathrm{E}$ supplementation on performance, nutrient digestibility, some blood traits, lipid peroxidation and antioxidant defence of male broilers. J Sci Food Agric. 2011;91:1277-82. https://doi.org/10.1002/jsfa.4311

28. Singh H, Sodhi S, Kaur R. Effects of dietary supplements of selenium, vitamin E or combinations of the two on antibody responses of broilers. Br Poult Sci. 2006;47:714-9. https://doi. org/10.1080/00071660601040079

29. Jo C, Ahn DU. Fluorometric analysis of 2-thiobarbituric acid reactive substances in turkey. Poult Sci. 1998;77:475-80. https://doi.org/10.1093/ps/77.3.475

30. Aebi H. Catalase in vitro. Methods Enzymol. 1984;105:121-6. https://doi.org/10.1016/S00766879(84)05016-3

31. Natt MP, Herrick CA. A new blood diluent for counting the erythrocytes and leucocytes of the chicken. Poult Sci. 1952;31:735-8. https://doi.org/10.3382/ps.0310735

32. Benjamin MM. Outline of veterinary clinical pathology. Ames, IA: Iowa State University Press; 1978.

33. Esmaillzadeh A, Tahbaz F, Gaieni I, Alavi-Majd H, Azadbakht L. Cholesterol-lowering effect of concentrated pomegranate juice consumption in type II diabetic patients with hyperlipidemia. Int J Vitam Nutr Res. 2006;76:147-51. https://doi.org/10.1024/0300-9831.76.3.147

34. Delhanty JJ, Solomon JB. The nature of antibodies to goat erythrocytes in the developing chicken. Immunology. 1966;11:103-13.

35. SAS Institute. Base SAS 9.4 procedures guide. Cary, NC: SAS Institute; 2015.

36. Saleh H, Golian A, Kermanshahi H, Mirakzehi MT. Antioxidant status and thigh meat quality of broiler chickens fed diet supplemented with $\alpha$-tocopherolacetate, pomegranate pomace and pomegranate pomace extract. Ital J Anim Sci. 2018;17:386-95. https://doi.org/10.1080/18 28051X.2017.1362966

37. Engberg RM, Lauridsen C, Jensen SK, Jakobsen K. Inclusion of oxidized vegetable oil in broiler diets. Its influence on nutrient balance and on the antioxidative status of broilers. Poult Sci. 1996;75:1003-11. https://doi.org/10.3382/ps.0751003

38. Tavárez MA, Boler DD, Bess KN, Zhao J, Yan F, Dilger AC, et al. Effect of antioxidant inclusion and oil quality on broiler performance, meat quality, and lipid oxidation. Poult Sci. 2011;90:922-30. https://doi.org/10.3382/ps.2010-01180

39. Abdel Baset S, Ashour EA, Abd El-Hack ME, El-Mekkawy MM. Effect of different levels of pomegranate peel powder and probiotic supplementation on growth, carcass traits, blood serum metabolites, antioxidant status and meat quality of broilers. Anim Biotechnol. 2020:1-11. https://doi.org/10.1080/10495398.2020.1825965

40. Lin YF, Tsai HL, Lee YC, Chang SJ. Maternal vitamin E supplementation affects the antioxidant capability and oxidative status of hatching chicks. J Nutr. 2005;135:2457-61. https://doi. org/10.1093/jn/135.10.2457 
41. Saleh H. Effects of natural antioxidant on the immune response, antioxidant enzymes and hematological broilers chickens. Iran Vet J. 2015;11:67-79. https://doi.org/10.22055/ ivj.2015.11590

42. Yesilbag D, Eren M, Agel H, Kovanlikaya A, Balci F. Effects of dietary rosemary, rosemary volatile oil and vitamin $\mathrm{E}$ on broiler performance, meat quality and serum SOD activity. Br Poult Sci. 2011;52:472-82. https://doi.org/10.1080/00071668.2011.599026

43. Verma AR, Vijayakumar M, Mathela CS, Rao CV. In vitro and in vivo antioxidant properties of different fractions of Moringa oleifera leaves. Food Chem Toxicol. 2009;47:2196-201. https://doi.org/10.1016/j.fct.2009.06.005

44. Faria A, Monteiro R, Mateus N, Azevedo I, Calhau C. Effect of pomegranate (Punica granatum) juice intake on hepatic oxidative stress. Eur J Nutr. 2007;46:271-8. https://doi. org/10.1007/s00394-007-0661-z

45. Akuru EA, Oyeagu CE, Mpendulo TC, Rautenbach F, Oguntibeju OO. Effect of pomegranate (Punica granatum L) peel powder meal dietary supplementation on antioxidant status and quality of breast meat in broilers. Heliyon. 2020;6:e5709. https://doi.org/10.1016/j.heliyon.2020.e05709

46. Zhang GF, Yang ZB, Wang Y, Yang WR, Jiang SZ, Gai GS. Effects of ginger root (Zingiber officinale) processed to different particle sizes on growth performance, antioxidant status, and serum metabolites of broiler chickens. Poult Sci. 2009;88:2159-66. https://doi.org/10.3382/ ps.2009-00165

47. Hori T, Uemoto S, Chen F, Gardner LB, Baine AMT, Hata T, et al. Oxidative stress and extracellular matrices after hepatectomy and liver transplantation in rats. World J Hepatol. 2014;6:72-84. https://doi.org/10.4254/wjh.v6.i2.72

48. Bueno JPR, de Mattos Nascimento MRB, da Silva Martins JM, Marchini CFP, Gotardo LRM, de Sousa GMR, et al. Effect of age and cyclical heat stress on the serum biochemical profile of broiler chickens. Semina: Ciênc Agrár. 2017;38:1383-92. https://doi. org/10.5433/1679-0359.2017v38n3p1383

49. Delles RM, Xiong YL, True AD, Ao T, Dawson KA. Dietary antioxidant supplementation enhances lipid and protein oxidative stability of chicken broiler meat through promotion of antioxidant enzyme activity. Poult Sci. 2014;93:1561-70. https://doi.org/10.3382/ps.2013-03682

50. Surai PF, Kochish II, Fisinin VI, Kidd MT. Antioxidant defence systems and oxidative stress in poultry biology: an update. Antioxidants. 2019;8:235. https://doi.org/10.3390/antiox8070235

51. Pan JQ, Tan X, Li JC, Sun WD, Wang XL. Effects of early feed restriction and cold temperature on lipid peroxidation, pulmonary vascular remodelling and ascites morbidity in broilers under normal and cold temperature. Br Poult Sci. 2005;46:374-81. https://doi. org/10.1080/00071660500098152

52. Mahmoud KZ, Hijazi AA. Effect of vitamin A and/or E on plasma enzymatic antioxidant systems and total antioxidant capacity of broiler chickens challenged with carbon tetrachloride.J Anim Physiol Anim Nutr. 2007;91:333-40. https://doi.org/10.1111/j.1439-0396.2006.00659.x

53. Olson JA. Benefits and liabilities of vitamin A and carotenoids. J Nutr. 1996;126:1208S-12S. https://doi.org/10.1093/jn/126.suppl_4.1208S

54. İnal M, Kanbak G, Şen S, Akyüz F, Sunal E. Antioxidant status and lipid peroxidation in hemodialysis patients undergoing erythropoietin and erythropoietin-vitamin E combined therapy. Free Radic Res. 1999;31:211-6. https://doi.org/10.1080/10715769900300771

55. Tekce E, Çınar K, Bayraktar B, Takma Ç, Gül M. Effects of an essential oil mixture added to drinking water for temperature-stressed broilers: performance, meat quality, and thiobarbituric acid-reactive substances. J Appl Poult Res. 2020;29:77-84. https://doi.org/10.3382/japr/pfz030 
56. Sahin K, Sahin N, Onderci M, Gursu MF, Issi M. Vitamin C and E can alleviate negative effects of heat stress in Japanese quails. J Food Agric Environ. 2003;1:244-9. https://doi. org/10.1234/4.2003.373

57. Huang THW, Peng G, Kota BP, Li GQ, Yamahara J, Roufogalis BD, et al. Anti-diabetic action of Punica granatum flower extract: activation of PPAR- $\gamma$ and identification of an active component. Toxicol Appl Pharmacol. 2005;207:160-9. https://doi.org/10.1016/j.taap.2004.12.009

58. Rajani J, Torshizi MAK, Rahimi S. Control of ascites mortality and improved performance and meat shelf-life in broilers using feed adjuncts with presumed antioxidant activity. Anim Feed Sci Technol. 2011;170:239-45. https://doi.org/10.1016/j.anifeedsci.2011.09.001

59. Smulikowska S, Pastuszewska B, Świech E, Ochtabińska A, Mieczkowska A, Nguyen VC, et al. Tannin content affects negatively nutritive value of pea for monogastrics. J Anim Feed Sci. 2001;10:511-23. https://doi.org/10.22358/jafs/68004/2001

60. Marzo F, Urdaneta E, Santidrián S. Liver proteolytic activity in tannic acid-fed birds. Poult Sci. 2002;81:92-4. https://doi.org/10.1093/ps/81.1.92

61. Kishawy ATY, Amer SA, Abd El-Hack ME, Saadeldin IM, Swelum AA. The impact of dietary linseed oil and pomegranate peel extract on broiler growth, carcass traits, serum lipid profile, and meat fatty acid, phenol, and flavonoid contents. Asian-Australas J Anim Sci. 2019;32:1161-71. https://doi.org/10.5713/ajas.18.0522

62. Rajabian T, Husseini HF, Karami M, Rasooli I, Faghihzadeh S. Effect of pomegranate fruit juice and seed oil on serum lipid levels and atherosclerosis development in hypercholesterolemic rabbits. J Med Plants. 2008;7:93-104.

63. Manach C, Scalbert A, Morand C, Rémésy C, Jiménez L. Polyphenols: food sources and bioavailability. Am J Clin Nutr. 2004;79:727-47. https://doi.org/10.1093/ajcn/79.5.727

64. Jung S, Choe JH, Kim B, Yun H, Kruk ZA, Jo C. Effect of dietary mixture of gallic acid and linoleic acid on antioxidative potential and quality of breast meat from broilers. Meat Sci. 2010;86:520-6. https://doi.org/10.1016/j.meatsci.2010.06.007

65. Lee SH, Shinde PL, Choi JY, Kwon IK, Lee JK, Pak SI, et al. Effects of tannic acid supplementation on growth performance, blood hematology, iron status and faecal microflora in weanling pigs. Livest Sci. 2010;131:281-6. https://doi.org/10.1016/j.livsci.2010.04.013

66. Bayraktar B, Tekce E, Aksakal V, Gül M, Takma Ç, Bayraktar S, et al. Effect of the addition of essential fatty acid mixture to the drinking water of the heat stress broilers on adipokine (Apelin, BDNF) response, histopathologic findings in liver and intestines, and some blood parameters. Ital J Anim Sci. 2020;19:656-66. https://doi.org/10.1080/1828051X.2020.1778548

67. Khan-Merchant N, Penumetcha M, Meilhac O, Parthasarathy S. Oxidized fatty acids promote atherosclerosis only in the presence of dietary cholesterol in low-density lipoprotein receptor knockout mice.J Nutr. 2002;132:3256-62. https://doi.org/10.1093/jn/132.11.3256

68. Arslan M, Ozcan M, Matur U, Çotelioglu U, Ergul E. The effects of vitamin E on some blood parameters in broilers. Turk J Vet Anim Sci. 2001;25:711-6.

69. Franchini A, Giordani G, Meluzzi A, Manfreda G. High doses of vitamin E in the turkey diet. Arch Geflügelkunde. 1990;54:6-10.

70. Smith TL, Kummerow FA. Effect of dietary vitamin $\mathrm{E}$ on plasma lipids and atherogenesis in restricted ovulator chickens. Atherosclerosis. 1989;75:105-9. https://doi.org/10.1016/00219150(89)90166-4

71. Wu Y, Zhu C, Zhang Y, Li Y, Sun J. Immunomodulatory and antioxidant effects of pomegranate peel polysaccharides on immunosuppressed mice. Int J Biol Macromol. 2019;137:504-11. https://doi.org/10.1016/j.ijbiomac.2019.06.139

72. Delimont NM, Haub MD, Lindshield BL. The impact of tannin consumption on iron bio- 
availability and status: a narrative review. Curr Dev Nutr. 2017;1:1-12. https://doi.org/10.3945/ cdn.116.000042

73. Guo Q, Zhao B, Li M, Shen S, Xin W. Studies on protective mechanisms of four components of green tea polyphenols against lipid peroxidation in synaptosomes. Biochim Biophys ActaLipids Lipid Metab. 1996;1304:210-22. https://doi.org/10.1016/S0005-2760(96)00122-1

74. Kumar KP, Reddy V, Prakash MG. Effect of supplementing pomegranate (Punica granatum) peel extract on serum biochemical parameters and immune response in broilers during summer. Pharm Innov J. 2018;7:591-601.

75. Pertiwi H, Rochmi SE, Dadi TB. Blood parameter profile and helminthiasis identificationon in sheep fed with diets rich in polyunsaturated fatty acid (PUFA). Indian Vet J. 2019;96:11-3.

76. Bayraktar B, Tekce E. Effects of varying essential oil mixture concentrations applied underconditions of different temperature stress on cardiac markers and other blood parameters. Braz J Poult Sci. 2019;21. https://doi.org/10.1590/1806-9061-2019-1119

77. arıca Ş, Ürkmez D. The use of grape seed-, olive leaf- and pomegranate peel-extracts as alternative natural antimicrobial feed additives in broiler diets. Eur Poult Sci. 2016;80:1-13. https:// doi.org/10.1399/eps.2016.121

78. Ng CY, Kamisah Y, Faizah O, Jubri Z, Qodriyah HMS, Jaarin K. Involvement of inflammation and adverse vascular remodelling in the blood pressure raising effect of repeatedly heated palm oil in rats. Int J Vasc Med. 2012;2012:404025. https://doi.org/10.1155/2012/404025

79. Ross RG, Selvasubramanian S, Jayasundar S. Immunomodulatory activity of Punica granatum in rabbits—a preliminary study. J Ethnopharmacol. 2001;78:85-7. https://doi.org/10.1016/ S0378-8741(01)00287-2

80. Saeed M, Naveed M, BiBi J, Kamboh AA, Arain MA, Shah QA, et al. The promising pharmacological effects and therapeutic/medicinal applications of Punica granatum L. (pomegranate) as a functional food in humans and animals. Recent Pat Inflammation Allergy Drug Discovery. 2018;12:24-38. https://doi.org/10.2174/1872213X12666180221154713

81. Ackermann-Gäumann R, Tritten ML, Hassan M, Lienhard R. Comparison of three commercial IgG and IgM ELISA kits for the detection of tick-borne encephalitis virus antibodies. Ticks Tick Borne Dis. 2018;9:956-62. https://doi.org/10.1016/j.ttbdis.2018.03.031

82. Abdel-Moneim AME, Shehata AM, Alzahrani SO, Shafi ME, Mesalam NM, Taha AE, et al. The role of polyphenols in poultry nutrition. J Anim Physiol Anim Nutr. 2020;104:1851-66. https://doi.org/10.1111/jpn.13455

83. Reda FM, El-Saadony MT, Elnesr SS, Alagawany M, Tufarelli V. Effect of dietary supplementation of biological curcumin nanoparticles on growth and carcass traits, antioxidant status, immunity and caecal microbiota of Japanese quails. Animals. 2020;10:754. https://doi. org/10.3390/ani10050754

84. Dibner JJ, Atwell CA, Kitchell ML, Shermer WD, Ivey FJ. Feeding of oxidized fats to broilers and swine: effects on enterocyte turnover, hepatocyte proliferation and the gut associated lymphoid tissue. Anim Feed Sci Technol. 1996;62:1-13. https://doi.org/10.1016/S03778401(96)01000-0 